\title{
Consortia of bioactives in supercritical carbon dioxide extracts of mustard and small cardamom seeds lower serum cholesterol levels in rats: new leads for hypocholesterolaemic supplements from spices
}

\author{
Soumi Chakraborty ${ }^{1}$, Kaninika Paul ${ }^{1}$, Priyanka Mallick ${ }^{2}$, Shrabani Pradhan ${ }^{3}$, Koushik Das ${ }^{3}$, \\ Saikat Chakrabarti ${ }^{2}$, Dilip Kumar Nandi $^{3}$ and Paramita Bhattacharjee ${ }^{1} *$ (D) \\ ${ }^{1}$ Department of Food Technology and Biochemical Engineering, Jadavpur University, Kolkata 700032, India \\ ${ }^{2}$ Division of Structural Biology and Bioinformatics, CSIR-Indian Institute of Chemical Biology, 4, Raja S.C. Mullick Road, Kolkata 700032, India \\ ${ }^{3}$ Research Unit developed by Department of Physiology, Nutrition and Microbiology, Raja N.L. Khan Women's College, Midnapore 721102, West \\ Bengal, India
}

(Received 18 April 2019 - Accepted 17 July 2019)

Journal of Nutritional Science (2019), vol. 8, e32, page 1 of 15

doi:10.1017/jns.2019.28

Abstract

Melatonin-rich and 1,8-cineole-rich extracts have been successfully obtained from yellow mustard (YM) and small cardamom (SC) seeds, respectively, employing green technology of supercritical $\mathrm{CO}_{2}\left(\mathrm{SC}_{-} \mathrm{CO}_{2}\right)$ extraction. Chemical profiling confirmed the presence of melatonin and 1,8-cineole and coextractants in the respective extracts. Electron paramagnetic resonance spectroscopy attested strong antioxidant activities of the extracts foregoing panassay interference compounds involved in spectroscopic analysis. These extracts also exhibited synergistic efficacies greater than unity confirming antioxidant synergy among the co-extracted bioactives therein. To ascertain hypocholesterolaemic efficacies, these extracts were co-administered orally with Triton $\mathrm{X}$ (at the pre-optimised dose of $175 \mathrm{mg} / \mathrm{kg}$ body weight (BW)) to Wistar albino rats at doses of 550, $175 \mathrm{and} 55 \mathrm{mg} / \mathrm{kg}$ BW. Serum total cholesterol levels in the rats were monitored on days 3, 7, 15 and 21. On day 21, total cholesterol level reduced appreciably by $49.44 \%$ in rats treated with YM seed extract and by $48.95 \%$ in rats treated with SC seed extract, comparable with atorvastatin-administered rats (51.09\%). Either extract demonstrated inhibitory effects on hepatic 3-hydroxy-3-methyl-glutaryl-CoA (HMG-CoA) reductase activity. A molecular docking exercise identified specific compounds in the extracts which possessed binding affinities comparable with therapeutically used HMG-CoA reductase inhibitors. In silico and in vivo studies concertedly concluded that the consortium of bioactive components in the extracts cannot be considered as invalid metabolic panaceas and therefore these 'green' extracts could be safely subjected to clinical studies as preventive biotherapeutics for hypercholesterolaemia. These extracts could be consumed per se as hypocholesterolaemic supplements or could be ingredients of new spice-based therapeutic foods.

Key words: Supercritical carbon dioxide extraction: Yellow mustard seeds: Small cardamom seeds: Hypocholesterolaemic activity: HMG-CoA reductase

The seeds of spice crops yellow mustard (Brassica campestris), commonly known as 'field mustard', and small cardamom (Elettaria cardamomum), the 'Queen of spices', are consumed as culinary condiments in India and also across the globe. These spices are reportedly known to possess strong antioxidant, anti-inflammatory and antimicrobial properties ${ }^{(1,2)}$.

Abbreviations: AI, atherogenic index; BW, body weight; EDX, energy dispersive X-rays; EPR, electron paramagnetic resonance; FT-IR, Fourier transformed IR spectroscopy; GOLD, Genetic Optimization for Ligand Docking; HDL-C, HDL-cholesterol; HED, human equivalent dose; HMG-CoA, 3-hydroxy-3-methyl-glutaryl-CoA; LC-ESI-MS, liquid chromatography-electrospray ionisation MS; LDL-C, LDL-cholesterol; OECD, Organization of Economic Co-operation and Development; PDB, protein data bank; $\mathrm{SC}$, small cardamom; $\mathrm{SC}_{\text {best }}$, small cardamom seed extract obtained at the optimum conditions of $\mathrm{SC}^{-\mathrm{CO}_{2}}$; $\mathrm{SC}_{-} \mathrm{CO}_{2}$, supercritical CO 2 ; TC, total cholesterol; $\mathrm{YM}$, yellow mustard; $\mathrm{YM}_{\text {best, }}$ yellow mustard seed extract obtained at the optimum conditions of $\mathrm{SC}-\mathrm{CO}_{2}$.

* Corresponding author: Paramita Bhattacharjee, fax +91 332414 6822, email paramita.bhattacharjee@jadavpuruniversity.in 
It has been demonstrated that consumption of $3 \mathrm{~g}$ whole cardamom per $\mathrm{d}$ has antihypertensive, anti-inflammatory and antioxidant activities in humans ${ }^{(3,4)}$. However, there is no documented evidence on similar therapeutic benefits of whole mustard seeds in humans.

Despite noteworthy benefits of the above seeds, consumption of the whole seeds per se and also as constituents (seasonings) of cooked foods for exploitation of the benefits of 'food synergy $^{(5)}$ is limited owing to their appreciably high Scoville heat unit values and thermal degradation of their constituent heat-sensitive bioactives. To forego these limitations, we have adopted the 'reductionism' $\operatorname{approach}^{(5)}$ to obtain 'bioactive-rich extracts' from these spices by employing the green technology of supercritical $\mathrm{CO}_{2}\left(\mathrm{SC}-\mathrm{CO}_{2}\right)$ extraction. The extraction parameters have been optimised (by statistical design of experiments and analysis) to yield extracts rich in their respective bioactive principles, namely melatonin-rich extract from yellow mustard (YM) seeds ${ }^{(6)}$ and 1,8-cineole-rich extract from small cardamom (SC) seeds ${ }^{(7)}$. These extracts have exhibited in vitro inhibition of cholesterol solubility in micellar solution $(60 \cdot 34-84.56 \%)^{(6,7)}$, which indicates possible inhibition of intestinal cholesterol absorption ${ }^{(8)}$.

Bisson $e t a l .{ }^{(9)}$ have recommended that it is crucial to verify the bioactivity of compounds before designating them as 'authentic natural leads'. Therefore, the above extracts have been subjected to rigorous in vitro chemical profiling and assessment of their antioxidative efficacies including synergism among the co-extracted antioxidants. All these in vitro findings prompted us to explore the efficacies of the aforesaid extracts in redressing in vivo hypercholesterolaemia in Wistar albino rats. Rat models have been selected owing to their physiological, anatomical and genetic similarities to human beings ${ }^{(10)}$. All in vivo studies were conducted in accordance with Organization of Economic Co-operation and Development (OECD) guidelines.

Triton X-100 is reportedly the classical cholesterol-inducing drug $^{(11,12)}$. Although the use of Triton X-100 in different doses in inducing hypercholesterolaemia in rats has been documented by several authors ${ }^{(12-15)}$, the rationale behind the choice of the said doses is not reported, implying non-specific selection of doses by researchers. Moreover, it is not apparent from the literature whether these randomly selected doses could achieve a stable hypercholesterolaemic condition in the experimental rats. This necessitated thorough optimisation of the dose of Triton X-100 in the present study to first achieve a stable hypercholesterolaemic condition in the Wistar rats to enable unambiguous judgement of the hypocholesterolaemic efficacies of the spice extracts thereafter. The extracts were then co-administered with the optimised dose of Triton $\mathrm{X}-100$ in rats to investigate their efficacies as preventive medicines for hypercholesterolaemia.

Therefore, the specific objectives of the present study are: (a) chemical profiling of the extracts by Fourier transformed IR spectroscopy (FT-IR), GC-MS and liquid chromatographyelectrospray ionisation MS (LC-ESI-MS); (b) evaluation of in vitro antioxidative efficacies in terms of their radical-scavenging potencies and synergistic effects (SE) among the co-extracted antioxidants; (c) optimisation of dose and duration of Triton $\mathrm{X}-100$ administration to induce a stable hypercholesterolaemic condition in Wistar rats with minimum toxicity effects on liver and kidney tissues; (d) to investigate the hypocholesterolaemic efficacies in terms of their lipid profiles and atheroprotective efficacies; and (e) investigation of the inhibitory effects of the extracts on 3-hydroxy-3-methyl-glutaryl-CoA (HMG-CoA) reductase (the key indicator of cholesterol biosynthesis pathway) activity.

It is envisaged that these spice extracts would primarily act as inhibitors of HMG-CoA reductase and thereby lower serum total cholesterol (TC) levels, and/or would exhibit a secondary effect by scavenging reactive oxygen species produced during hypercholesterolaemia and therefore mitigate in vivo lipid peroxidation in the animals. Although few in vivo studies exist on efficacies of mustard (Brassica juncea) and small cardamom (E. cardamomum) seeds in redressing hypercholesterolaemia in animal models ${ }^{(16,17)}$, only changes in lipid profiles of the animals have been reported.

The present study is the first systematic detailed study in accordance with OECD guidelines for the elucidation of hypocholesterolaemic efficacies of $\mathrm{SC}-\mathrm{CO}_{2}$ extracts of SC and YM seeds. Additionally, molecular docking studies were performed by docking the major extract constituents with HMG-CoA reductase, followed by comparative evaluation of their binding potentials with a standard statin-based drug. This exercise allowed us to identify which chemical compounds among the major extracted constituents inhibited HMG-CoA reductase activity. The findings of in silico and in vivo studies were then corroborated to eliminate ambiguity in conferring these spice extracts as novel biotherapeutics. The outcome of the present study can safely be extrapolated to redress hypercholesterolaemia in humans. These extracts would serve as hypocholesterolaemic supplements or could be ingredients for new spice-based therapeutic foods or drugs.

\section{Materials and methods}

\section{Materials}

The authenticated $\mathrm{B}_{9}$ species of YM seeds (B. campestris) were provided by IRDM and authenticated Alleppey green cardamom (E. cardamomum) seeds (of export quality) were procured from Spices Board. Specialty chemicals such as melatonin (99\% pure), 1,8-cineole (99\% pure) and Triton X-100 (99\% pure) were procured from Sigma. The pure standards of $\alpha$-terpineol, $\alpha$-terpinyl acetate, linalool and limonene were gifted by M/s Keva Flavours Pvt Ltd (Mumbai, India). Food-grade $\mathrm{CO}_{2}$ was purchased from BOC India Ltd. An SPE-ED matrix for SFE vessel packing and an SPE-ED SPE cartridge were procured from Applied Separations. All the chemicals for biochemical tests were collected from Merck Specialities Pvt. Ltd and HiMedia Laboratories Pvt. Ltd.

\section{Supercritical carbon dioxide extraction of ayurceuticals: melatonin from yellow mustard and 1,8-cineole from small cardamom seeds}

A laboratory scale 'SCF Green Technology SPE-ED SFE 2 model' (Applied Separations) was used for $\mathrm{SC}-\mathrm{CO}_{2}$ extractions 


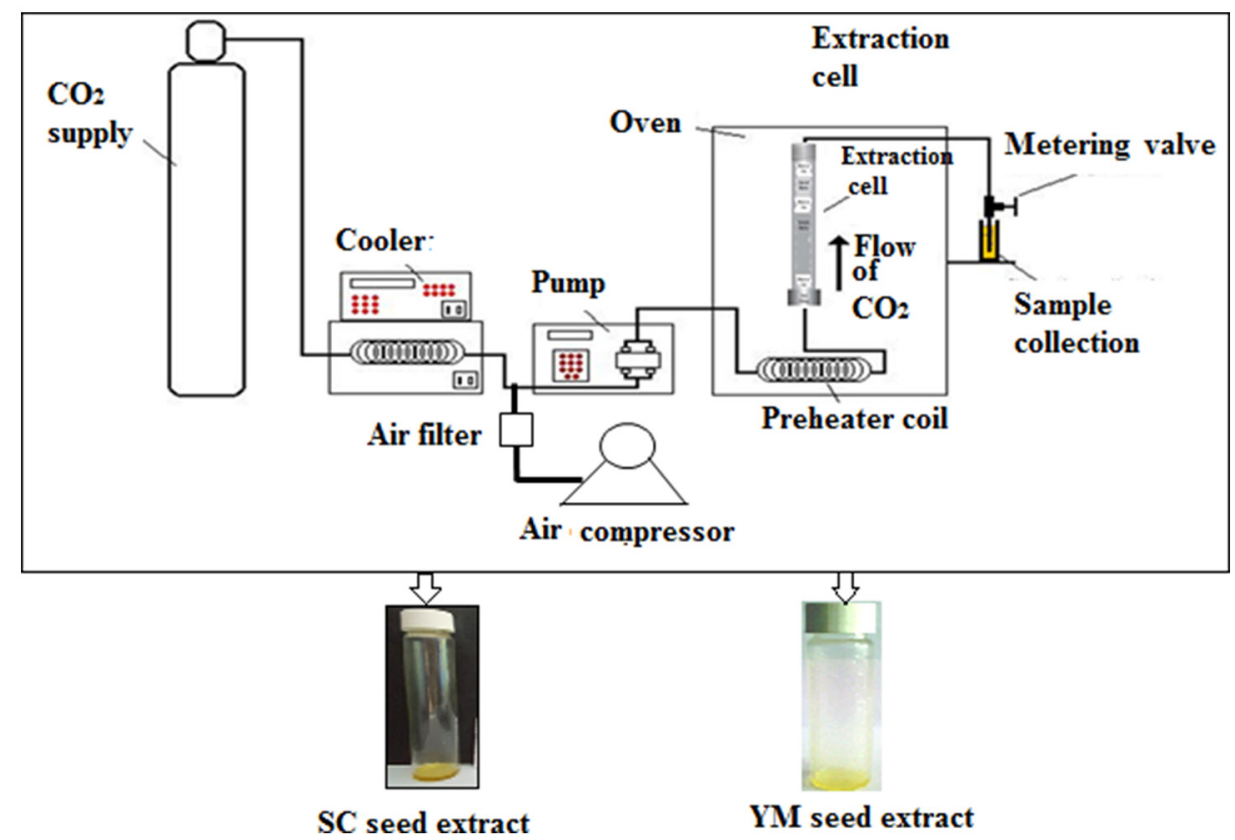

Fig. 1. Schematic diagram of the SPE-ED SFE unit of Applied Separations, USA. SC, small cardamom; YM, yellow mustard.

of melatonin and 1,8-cineole from YM and SC seeds, respectively $^{(6,7)}$ (Fig. 1). The optimised conditions that provided the maximum yield of melatonin were a sample size of $30 \mathrm{~g}\left(d_{\mathrm{p}}=0.5 \pm\right.$ $0.01 \mathrm{~mm})$ of $\mathrm{YM}$ seeds at a pressure of $300 \mathrm{bar}$ at $50^{\circ} \mathrm{C}$ and $120 \mathrm{~min}$ extraction time at a flow rate of 2 litres/min of gaseous $\mathrm{CO}_{2}^{(6)}$. The optimised conditions that provided the maximum yield of 1,8-cineole were a sample size of $25 \mathrm{~g}\left(d_{\mathrm{p}}=0.5 \pm\right.$ $0.01 \mathrm{~mm}$ ) of SC seeds at a pressure of $200 \mathrm{bar}, 50^{\circ} \mathrm{C}, 90 \mathrm{~min}$ extraction time and a flow rate of $\mathrm{CO}_{2}=2$ litres $/ \mathrm{min}^{(7)}$. The extracts of YM and SC seeds obtained at the optimum conditions of $\mathrm{SC}-\mathrm{CO}_{2}$ were designated as $\mathrm{SC}_{\text {best }}$ and $\mathrm{YM}_{\text {best }}$, respectively.

\section{Chemical profiling of $S C_{\text {best }}$ and $Y M_{\text {best }}$}

Quantification of melatonin in $Y M_{\text {best }}$ and 1,8-cineole in $S C_{\text {best }}$ Melatonin in $\mathrm{YM}_{\text {best }}$ was quantified by HPLC according to the method reported by Chakraborty \& Bhattacharjee ${ }^{(6)}$ while quantification of 1,8-cineole in $\mathrm{SC}_{\text {best }}$ was conducted densitometrically using high-performance TLC (HPTLC) in accordance with the method described by Ghosh et al. ${ }^{(1)}$. Both HPLC and HPTLC chromatograms suggested the presence of other co-extractants in the extracts in addition to their active principles (discussed later).

Fourier transformed IR analyses of $S C_{\text {best }}$ and $Y M_{\text {best }}$ extracts. FT-IR analyses of $\mathrm{SC}_{\text {best }}$ and $\mathrm{YM}_{\text {best }}$ were performed to preliminarily identify the co-extracted compounds present in the extracts. The extracts were placed on $\mathrm{KBr}$ pellets and subjected to a Spectrum 100 FT-IR spectrometer (PerkinElmer) with a light source of silicon carbide and frequency range of $1000-4000 / \mathrm{cm}$. The peaks of the FT-IR spectra were matched with available FT-IR spectra (Spectrabase ${ }^{\mathrm{TM}}$ database) of the other compounds present in $\mathrm{YM}_{\text {best }}$ (namely tocopherol, ascorbic acid, limonene and linalool, oleic acid) and $\mathrm{SC}_{\text {best }}$ (namely $\alpha$-terpinyl acetate, linalool, limonene and $\alpha$-terpineol) extracts.

Identification of co-extractants in the $\mathrm{YM}_{\text {best }}$ and $\mathrm{SC}_{\text {best. }}$. $\mathrm{YM}_{\text {best }}$ and $\mathrm{SC}_{\text {best }}$ were filtered using a $0.22 \mu \mathrm{m}$ syringe filter and then subjected to LC-ESI-MS and GC-MS, respectively, for identification of the co-extracted antioxidants. $\mathrm{YM}_{\text {best }}$ was diluted with $10 \%$ dimethyl sulfoxide (DMSO) and subjected to LC-ESI-MS analysis in accordance with the method reported by Halder et $a l^{(18)}$, with a few modifications. The LC system (Shimadzu Corporation) equipped with a binary pump (LC-20AD), an autosampler (SIL-20A), an online solvent degasser (DGU-20A3) and column oven (CTO-10AS) were used in this study. An aliquot $(10 \mu \mathrm{l})$ of diluted sample was injected into a C18 analytical column (Phenomenex Kinetex, $50 \mathrm{~mm} \times 3 \mathrm{~mm}$, internal diameter $5 \mu \mathrm{m}$ ). Mass spectrometric detection was performed in the multiple reactions monitoring mode.

$\mathrm{SC}_{\text {best }}$ was analysed using GC-MS to detect the presence of co-antioxidants therein in accordance with the method reported by Ghosh et al. ${ }^{(1)}$, with a few modifications. A Perkin Elmer GC Clarus 680 chromatograph (Perkin Elmer) equipped with a fused silica capillary column $(30 \times 0.25 \mathrm{~mm}$ internal diameter, $0.25 \mu \mathrm{m}$ film thickness) coupled to a Perkin Elmer Clarus SQ 8T mass Detector (Perkin Elmer) was employed for the analyses. Identification of the components of the extracts was based on matching the mass spectra with those available in the NIST (2000) library of compounds and from literature reports of mass spectra by Adams and others ${ }^{(19-21)}$.

Quality assessment of $Y M_{\text {best }}$ and $S_{\text {best }}$ in terms of their antioxidant efficacies. 2,2-Diphenyl-1-picrylhydrasyl (DPPH) radical scavenging activity: The antioxidant activities of $\mathrm{YM}_{\text {best }}$ and 
$\mathrm{SC}_{\text {best }}$ were primarily evaluated by DPPH radical scavenging activity employing the spectrophotometric method ${ }^{(22)}$ and expressed as $\mathrm{IC}_{50}(50 \%$ radical scavenging activity of $\mathrm{DPPH})$ values. However, there is possibility of obtaining false-positive absorbance $^{(9)}$ in this spectrophotometric assay owing to pan-assay interference compounds (PAINS). Therefore, the above extracts were further subjected to electron paramagnetic resonance (EPR) spectroscopic analysis for validation of their radical-scavenging activities.

Electron paramagnetic resonance analysis of extracts to eliminate the interference of 'pan-assay interference compounds' (PAINS): To eliminate PAINS in the above assay, the extracts were subjected to EPR spectroscopic analysis in accordance with the method reported by Chakraborty \& Bhattacharjee ${ }^{(())}$.

Assessment of antioxidant synergism in the extracts in terms of SE values: The antioxidants (discussed later) present in $\mathrm{YM}_{\text {best }}$ and $\mathrm{SC}_{\text {best }}$ may impede the antioxidative function of either melatonin or 1,8-cineole, if they do not act in synergism. Hence, in vitro synergism among 1,8-cineole, $\alpha$-terpinyl acetate, limonene, $\alpha$-terpineol and linalool in $\mathrm{SC}_{\text {best }}$ and that among melatonin, tocopherol, ascorbic acid, limonene and linalool in $\mathrm{YM}_{\text {best }}$ were determined in terms of SE values in accordance with the method described by Chakraborty \& Bhattacharjee ${ }^{(23)}$.

Safety assessment of $Y M_{\text {best }}$ and $S C_{\text {best }}$ in terms of heavy metals and in vivo acute toxicity. Since solventless SC-CO extractions of $\mathrm{YM}_{\text {best }}$ and $\mathrm{SC}_{\text {best }}$ did not necessitate further downstream processing and purification, the extracts thus obtained were analysed for the presence of heavy metals, if any. Also, in vivo acute toxicities of these were determined in Wistar albino rats to ensure safe oral administration thereafter.

\section{Presence of heavy metal toxicants}

Energy dispersive X-ray (EDX) analyses of $\mathrm{YM}_{\text {best }}$ and $\mathrm{SC}_{\text {best }}$ were performed in an EDX spectrometer (JSM-6700F; JEOL Ltd) to detect the presence of toxic metals such as $\mathrm{Ti}, \mathrm{Cu}, \mathrm{Pb}$, $\mathrm{Hg}, \mathrm{As}, \mathrm{Zn}, \mathrm{Se}, \mathrm{Ni}$, Mo and Si, if any. The analyses were carried out at $20 \mathrm{kV}$ using the JEOL detector under high vacuum (25-27 mbar).

\section{In vivo acute toxicity study}

As per OECD guidelines $423^{(24)}$, acute toxicities of SC-CO 2 extracts $\left(\mathrm{YM}_{\text {best }}\right.$ and $\left.\mathrm{SC}_{\text {best }}\right)$ were determined in terms of their $\mathrm{LD}_{50}$ values using the limit dose of $5000 \mathrm{mg}$ of extract/ $\mathrm{kg}$ body weight (BW). Wellness parameters of animals were observed and recorded systematically after $30 \mathrm{~min}, 1 \mathrm{~h}$, $2 \mathrm{~h}, 3 \mathrm{~h}, 4 \mathrm{~h}, 24 \mathrm{~h}$ and once regularly up to day 14 , postadministration of the said dose. The wellness parameters included changes in skin, fur, eyes and mucus membrane along with respiratory problems, changes in behavioural pattern, tremor, convulsions, salivations, diarrhoea, lethargy, sleep and mortality.
Evaluation of in vivo hypocholesterolaemic activities of $Y M_{\text {best }}$ and $S C_{\text {best }}$

Prior to co-administration of the extracts in Wister albino rats, the dose and duration of Triton X-100 administration were optimised to induce fast and stable hypercholesterolaemia in the animals. Groups of rats and details of in vivo experiments are schematically presented in Figs 2 and 3.

\section{Experimental animal acclimatisation and welfare-related assessments}

Male Wister albino rats (130-150 g) aged 2 months were procured from Rita Ghosh Private Ltd. The study was conducted in the laboratory of the Department of Physiology, Nutrition and Microbiology, Raja N.L. Khan Women's College, Midnapore, West Bengal, India, in the months of January to March 2017. The experiments were conducted as per approved guidelines of Institutional Animal Ethical Committee (IAEC) guidelines and CPCSEA (Committee for the Purpose of Control and Supervision of Experiments on Animals; registration no. 190/PO/Re/S/2016/CPCSEA).

The animals were maintained and acclimatised under standard environmental conditions $\left(17-23^{\circ} \mathrm{C}, 60 \pm 5 \%\right.$ relative humidity) for 3 weeks prior to the study. Acclimatised rats were selected randomly and three rats per polyacrylic cage $(30 \times 23 \times 10 \mathrm{~cm})$ were housed inside a temperature- and humidity-controlled room with $12 \mathrm{~h}$ dark-12 h light (180200 lux at day time) cycles. They were provided with standard rat feed (a mixture of wheat flour, Bengal gram flour, milk powder, salt and distilled water, on fresh w/w basis) and distilled water ad libitum throughout the experimental period. Animal care and personal hygiene of the researchers were maintained according to the Guide to the Care and Use of Experimental Animals ${ }^{(25)}$. Food intake and body weight were measured regularly during the experimental period.

\section{Acute toxicity study of Triton X-100}

Prior to standardisation of the dose of Triton X-100, an acute toxicity study of Triton X-100 was conducted in accordance with the method described for assessment of toxicity of the extracts.

\section{Standardisation of dose of Triton X-100 for inducing hypercholesterolaemia}

After overnight fasting, rats were injected intraperitoneally (Fig. 2) with $17 \cdot 5,55$ and $175 \mathrm{mg} / \mathrm{kg} \mathrm{BW}$ doses of Triton $\mathrm{X}-100$ prepared in $10 \%$ dimethyl sulfoxide (DMSO) solution, in accordance with a dose progression factor of 3.2 times as per OECD guidelines $425^{(26)}$ (Fig. 3). Triton X-100 was administered in the morning at 09.00 hours. To induce fast and stable hypercholesterolaemia, the rats were injected intraperitoneally both in 'single' doses of Triton X-100 at 17.5, 55 and $175 \mathrm{mg} / \mathrm{kg} \mathrm{BW}$ and in 'multiple' doses (i.e. each dose of $17 \cdot 5,55$ and $175 \mathrm{mg} / \mathrm{kg} \mathrm{BW}$ administered daily for 3 consecutive days). 


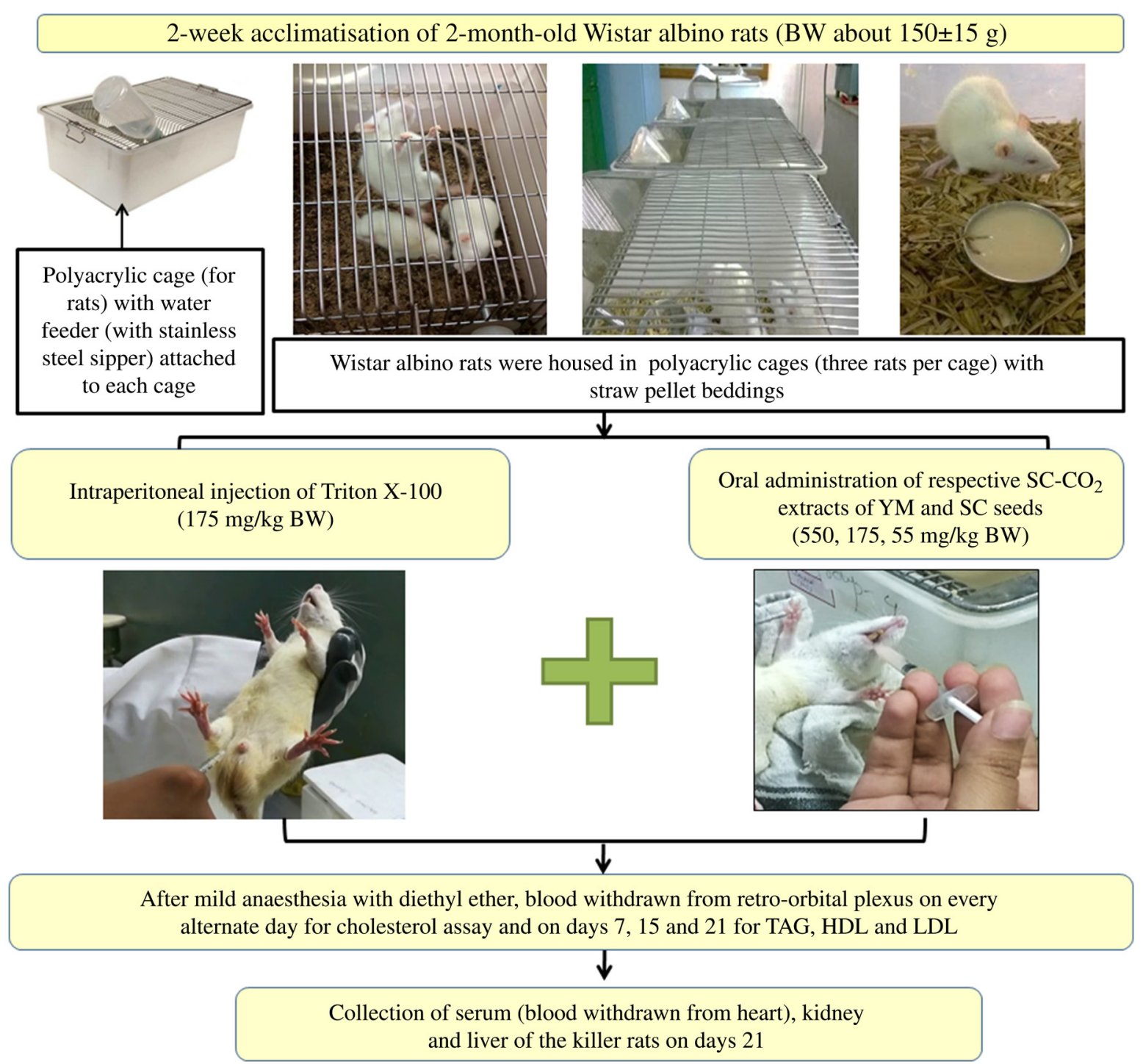

Fig. 2. Schematic representation of the in vivo experimental study. BW, body weight; $\mathrm{SC}-\mathrm{CO}_{2}$, supercritical carbon dioxide; $\mathrm{YM}$, yellow mustard; $\mathrm{SC}$, small cardamom.

Blood was withdrawn from the retro-orbital plexus of the rats on days $1,2,3$ and 5 (same time on each day) after mild anaesthesia with diethyl ether-soaked cotton. Since there were insignificant changes in TC levels of the rats on days 3 and 5, post-injection of a single dose of Triton $\mathrm{X}-100$ on day 1 (discussed later), the rats were killed on day 5. Heart blood collected from killed rats was centrifuged at $2000 \mathrm{~g}$ for $10 \mathrm{~min}$, the serum was collected and analysed for $\mathrm{TC}^{(27)}$, $\mathrm{TAG}^{(28)}$, HDL-cholesterol (HDL-C) ${ }^{(29)}$ and LDLcholesterol (LDL-C) ${ }^{(30)}$ levels using their respective standard kits. Hypercholesterolaemia in the rats was confirmed when serum cholesterol level remained stable at $200-210 \mathrm{mg} / \mathrm{dl}$ $(5 \cdot 18-5 \cdot 44 \mathrm{mmol} / \mathrm{l})^{(31)}$.

\section{Co-administration of $\mathrm{YM}_{\text {best }}$ and $\mathrm{SC}_{\text {best }}$ with Triton X-100}

Hypercholesterolaemia was induced in the rats by injecting an optimised dose (discussed in the Results and Discussion sections) of Triton X-100 (175 mg/ $\mathrm{kg} \mathrm{BW})$, intraperitoneally. Extracts were co-administered to the rats orally (a reliable method for administering substances into the gastrointestinal tract) at concentrations of 550,175 and $55 \mathrm{mg} / \mathrm{kg} \mathrm{BW}$, selected using the dose progression factor $3 \cdot 2^{(26)}$, after $1 \mathrm{~h}$ of single-dose Triton injection on day 1 and at 10.00 hours from day 2 onwards (Fig. 3). Blood was collected from the retro-orbital plexus of rats on days 3, 7, 15 and 21 (after mild anaesthesia with diethyl ether). It was observed that there were insignificant changes in the TC levels of the rats on days 15 and 21 (discussed later); the rats were therefore killed on day 21.

\section{Monitoring serum total cholesterol level after discontinuation of oral administration of $Y M_{\text {best }}$ and $S C_{\text {best }}$}

The optimised dose and duration of administration of $\mathrm{YM}_{\text {best }}$ and $\mathrm{SC}_{\text {best }}$ (obtained from above experiment) were found to be $550 \mathrm{mg} / \mathrm{kg} \mathrm{BW}$ and $15 \mathrm{~d}$, respectively (details of optimisation have been described later). Since there were negligible changes in serum TC levels of the extract-administered rats on days 15 and 21 , the serum cholesterol levels of rats were monitored on 

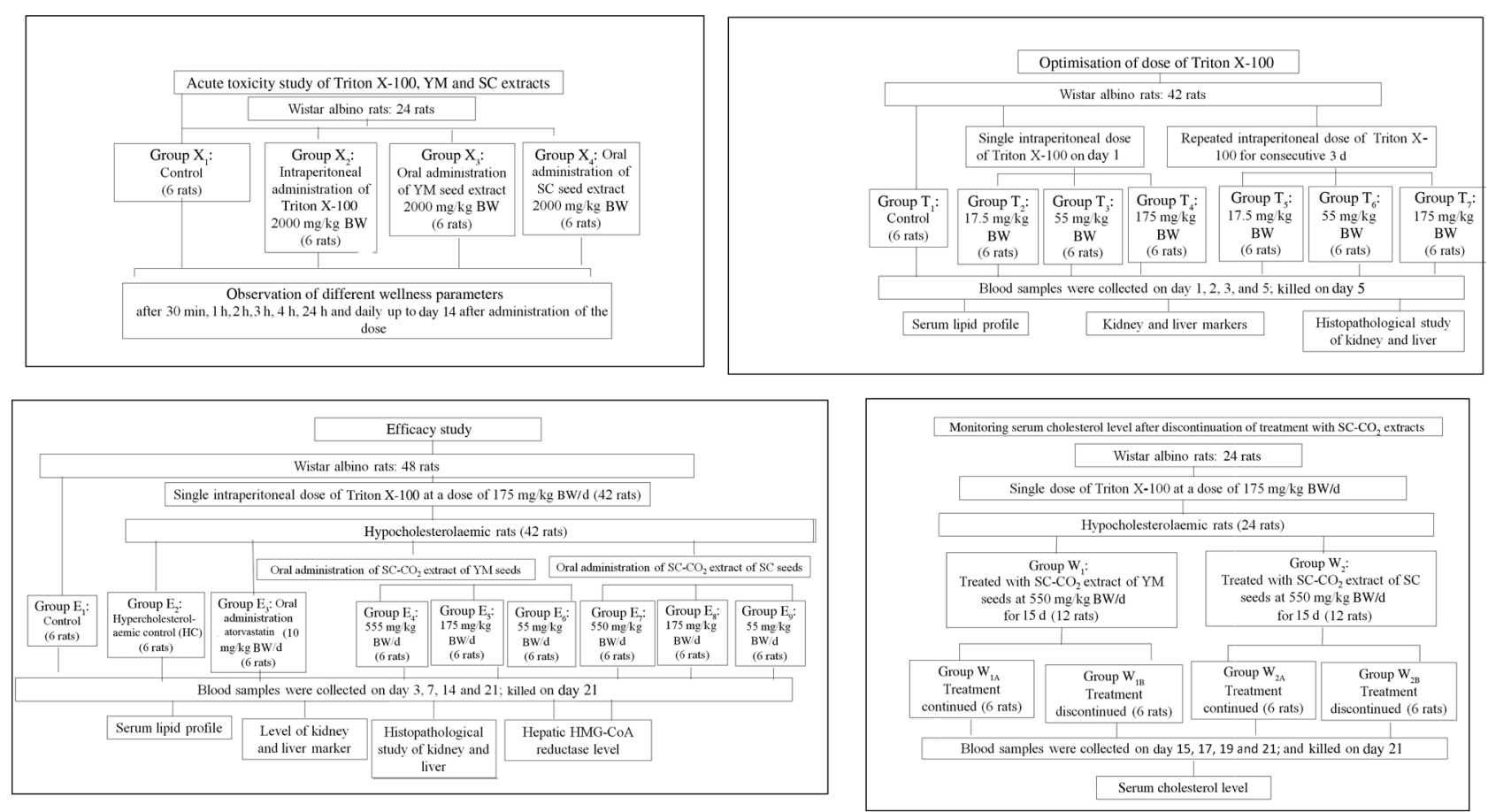

Fig. 3. Experimental design of the in vivo hypocholesterolaemic study. YM, yellow mustard; SC, small cardamom; BW, body weight; $\mathrm{SC}-\mathrm{CO}_{2}$, supercritical carbon dioxide; HC, healthy controls; HMG-CoA, 3-hydroxy-3-methyl-glutaryl-CoA.

days 15, 17, 19 and 21 (by withdrawing blood from the retroorbital plexus of the rats) after discontinuation of extract administration on day 15 to ascertain whether the same remained unaltered up to day 21. Concomitantly, the wellness (physical and/or psychological) parameters of the rats were also monitored.

\section{Withdrawal of blood samples and collection of organs for biochemical and histological assays}

On day 21, the rats were kept in a fasting condition overnight and killed by cervical dissipation on the following day. Blood was withdrawn from their aortas by cardiac puncture. The kidneys and livers of the animals were also recovered implementing standard dissection procedures ${ }^{(32)}$ of histological analyses.

\section{Biochemical estimation of plasma lipid profile and atherogenic indices}

The above collected serum samples (post-scarification) were subjected to TAG, HDL-C and LDL-C analyses on day 21 according to the above-mentioned standard methods. Serum VLDL-cholesterol level and atherogenic index (AI) were calculated according to Mallick et al. ${ }^{(3)}$ and Namani et al. ${ }^{(34)}$, respectively.

\section{Spectrophotometric determination of hepatic \\ 3-hydroxy-3-methyl-glutaryl-CoA reductase activity}

Liver samples were prepared in accordance with a reported method $^{(35)}$ for the assessment of HMG-CoA reductase activities in the rats. The liver $(0.2 \mathrm{~g})$ samples were minced and homogenised in ice-cold $50 \mathrm{~mm}-\mathrm{Tris}-\mathrm{HCl}$ buffer $(\mathrm{pH}$ $7 \cdot 5)$ and centrifuged at $1000 \mathrm{~g}$ at room temperature $\left(23 \pm 2^{\circ}\right.$ C) for $30 \mathrm{~min}$. The pellets were discarded and the supernatant fractions were subjected to the detection of HMG-CoA reductase activity, if any. HMG-CoA reductase activities in liver homogenates were estimated spectrophotometrically from the ratio of HMG-CoA:mevalonate (H:M), according to the method reported by Rao \& Ramakrishnan ${ }^{(36)}$.

\section{Histopathological studies and determination of liver and kidney markers}

To confirm whether there are any morphological changes in livers and kidneys of the experimental rats, the said organs were examined under light microscopy (Olympus). The levels of different liver (SGPT (serum glutamic pyruvic transaminase) and SGOT (serum glutamic-oxaloacetic transaminase)) and kidney markers (BUN (blood urea N), serum urea and creatinine) were determined to ascertain toxic effects of the extracts on the said organs, if any ${ }^{(32)}$.

\section{Estimation of human equivalent dose}

There are four different methods of extrapolation of dose from animals to humans, namely: dose by factor, similar drug, pharmacokinetically guided and comparative approaches ${ }^{(37)}$. In the present study, the 'dose by factor' approach has been used to estimate human equivalent dose (HED) values of $\mathrm{SC}_{\text {best }}$ and $\mathrm{YM}_{\text {best }}$ from their respective optimised animal doses. 


\section{Molecular docking studies with extract components and} 3-hydroxy-3-methyl-glutaryl-CoA reductase

The binding affinities of major components of $\mathrm{SC}_{\text {best }}$ and $\mathrm{YM}_{\text {best }}$ with HMG-CoA reductase were computed by molecular docking to identify the chemical compounds in the extracts which induced hypocholesterolaemia. The major components of the aforesaid extracts include limonene and linalool, as well as $\alpha$-terpinyl acetate, $\alpha$-terpineol and 1,8-cineole in $\mathrm{SC}_{\text {best }}$; and melatonin, tocopherol and ascorbic acid in $\mathrm{YM}_{\text {best. }}$. Therefore, the aforesaid components were compared structurally with the substrate (HMG-CoA) and inhibitors (statins) of HMG-CoA receptor protein. Since melatonin reportedly does not possess inhibitory activity on HMG-CoA reductase as evidenced in Sprague-Dawley rat models ${ }^{(38)}$, docking of this biomolecule with HMG-CoA reductase was not performed.

Three-dimensional structures of extract components and HMG-CoA reductase were retrieved from the PubChem database $^{(39)}$ and the solvent-accessible surface area of HMG-CoA reductase was generated using Chimera ${ }^{(40)}$. The top ten energetically preferred conformers of the above-mentioned biomolecules (except 1,8-cineole since it lacks rotatable bonds) were generated using FROG2 (FRee On line druG conformation generation) software ${ }^{(41)}$. Molecular docking of components (present in $\mathrm{SC}_{\text {best }}$ and $\mathrm{YM}_{\text {best }}$ ) was performed using one of the dimer structures of HMG-CoA receptor collected from the Protein Data Bank (PDB) ${ }^{(42)}$ (PDB ID: 1HWK). Initially, ingredient molecules were docked at the statin binding site of HMG-CoA receptor using the GOLD (Genetic Optimization for Ligand Docking) package ${ }^{(43)}$. GOLD software optimises the fitness score of many possible docking solutions using a genetic algorithm. The following parameters were used in the docking cycles: population size (10), selection pressure (1 100000$)$, number of operations (100 000), number of islands (5), niche size (2), crossover weight (95), mutate weight (95) and migrate weight (10). Docking solutions from various conformers were clustered based on their root mean square deviation (RMSD) representing structural similarity. Sub-clusters with a minimum of three solutions with RMSD $<2 \AA$ with each other were considered for further analysis. The top three scoring solutions (pose) from the largest cluster were selected for further comparison. For comparison purpose, rescoring of HMG-CoA (substrate) and statins (known inhibitors) of HMG-CoA receptor structures were carried out via the GOLD program. Five statin-bound structures (PDB ID: 1HW8, 1HW9, 1HWI, 1HWJ and 1HWL) and one HMG-CoA-bound HMG-CoA receptor structure (PDB ID: 1DQ9) were collected from the PDB.

We have also docked the active ingredient molecules at pockets other than the substrate/inhibitor binding sites. CASTp $^{(44)}$ and metaPockets ${ }^{(45)}$ programs were used to predict pockets in the HMG-CoA receptor protein. Commonly predicted pockets were selected for further docking where each active ingredient was docked onto all these pockets and a similar protocol (as described before) was applied to identify the most likely solutions. Docking scores of most likely solutions were plotted and the ligand-protein interactions were identified by the LigPlot program ${ }^{(46)}$.

\section{Statistical analyses of biochemical parameters}

The experimental results are expressed as means of the experimental data obtained from six rats in each group. Significant differences between mean values were determined by Student's $t$ test and Duncan's multiple-range test using STATISTICA 8.0 software (Statsoft). A $P$ value of $\leq 0 \cdot 05$ was used to verify the significance of the tests.
(A)

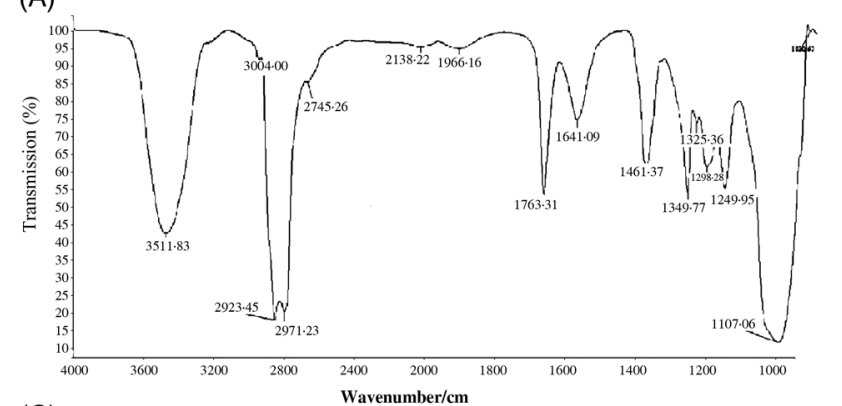

(C)

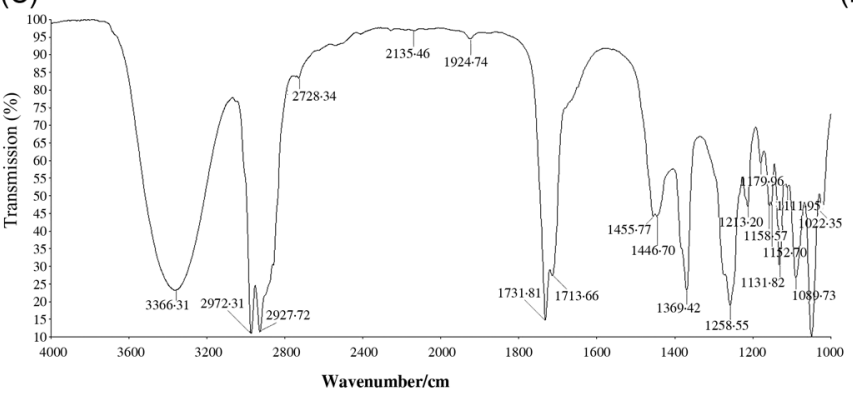

(B)

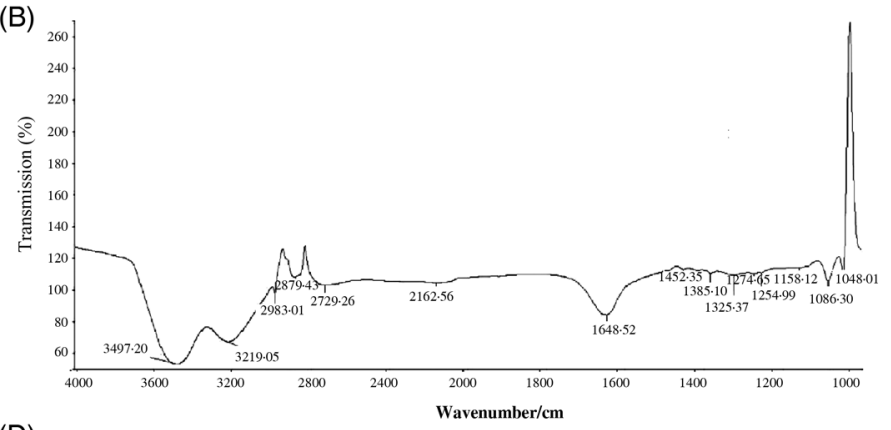

(D)

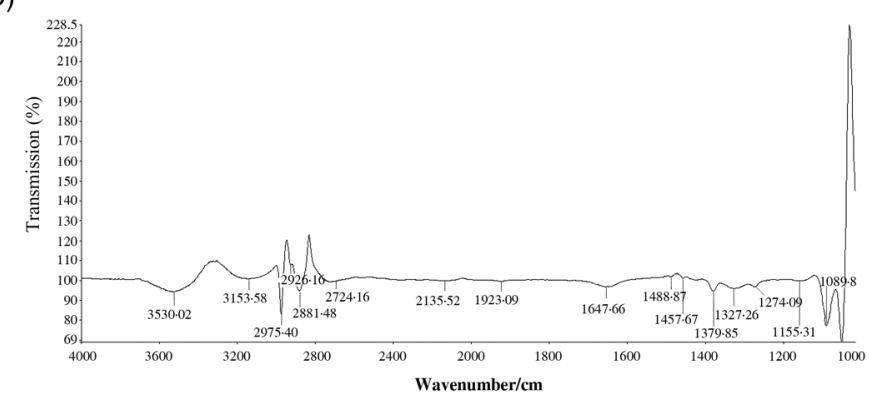

Fig. 4. Fourier transformed IR spectroscopy spectra of (A) melatonin, (B) supercritical carbon dioxide (SC-CO $\mathrm{CO}_{2}$ ) extract of yellow mustard seeds, (C) 1,8-cineole and (D) $\mathrm{SC}-\mathrm{CO}_{2}$ extract of small cardamom seeds. 


\section{Results}

\section{Chemical profiling, quality and safety of $Y_{\text {best }}$ and $\mathrm{SC}_{\text {best }}$}

The FT-IR spectra of $\mathrm{YM}_{\text {best }}$ and $\mathrm{SC}_{\text {best }}$ were analysed using the data published by Dyer ${ }^{(47)}$. The wavenumbers in the FT-IR spectrum of $\mathrm{SC}_{\text {best }}$ (Fig. 4) confirmed the presence of 1,8 -cineole and also indicated the presence of $\alpha$-terpinyl acetate, limonene, $\alpha$-terpineol and linalool ${ }^{(48-51)}$. The identities of these antioxidants were further confirmed by GC-MS analysis (Fig. 5). The relative peak percentage areas of 1,8-cineole, $\alpha$-terpinyl acetate, limonene, $\alpha$-terpineol and linalool in $\mathrm{SC}_{\text {best }}$ were $22.09,30.65,4.35,6.42$ and 0.40 , respectively.

In the case of $\mathrm{YM}_{\text {best }}$, the presence of $\mathrm{C}=\mathrm{C}(1463 \cdot 8 / \mathrm{cm})$, methoxy group $(2854 \cdot 55 / \mathrm{cm})$ and five membered ring $\mathrm{C}-\mathrm{C}$ multiple bond stretching $(1744 \cdot 12 / \mathrm{cm})$ in the FT-IR spectrum (Fig. 4) confirmed the presence of melatonin therein. Peaks in the range of $3008 / \mathrm{cm}$ (unsaturated double bonds, $=\mathrm{CH}$, is bonds) and $1654 / \mathrm{cm}(-\mathrm{C}=\mathrm{C}-$, cis bonds) suggested the presence of fatty acids in the extracts. The FT-IR spectra of standard oleic acid, limonene and tocopherol also suggested their presence in the extracts ${ }^{(52)}$. LC-ESI-MS (Fig. 5) analysis also confirmed the presence of the above co-extracted compounds in $\mathrm{YM}_{\text {best }}$.

$\mathrm{YM}_{\text {best }}$ and $\mathrm{SC}_{\text {best }}$ exhibited 62.89 and $83.87 \% \mathrm{DPPH}$ radical-scavenging activities, respectively, as revealed from their EPR spectra. The SE values of $\mathrm{YM}_{\text {best }}$ and $\mathrm{SC}_{\text {best }}$ were greater than unity for either extract, namely 1.09 and 1.16, respectively. EDX analyses revealed that no heavy metal was present in either extract.

(A)
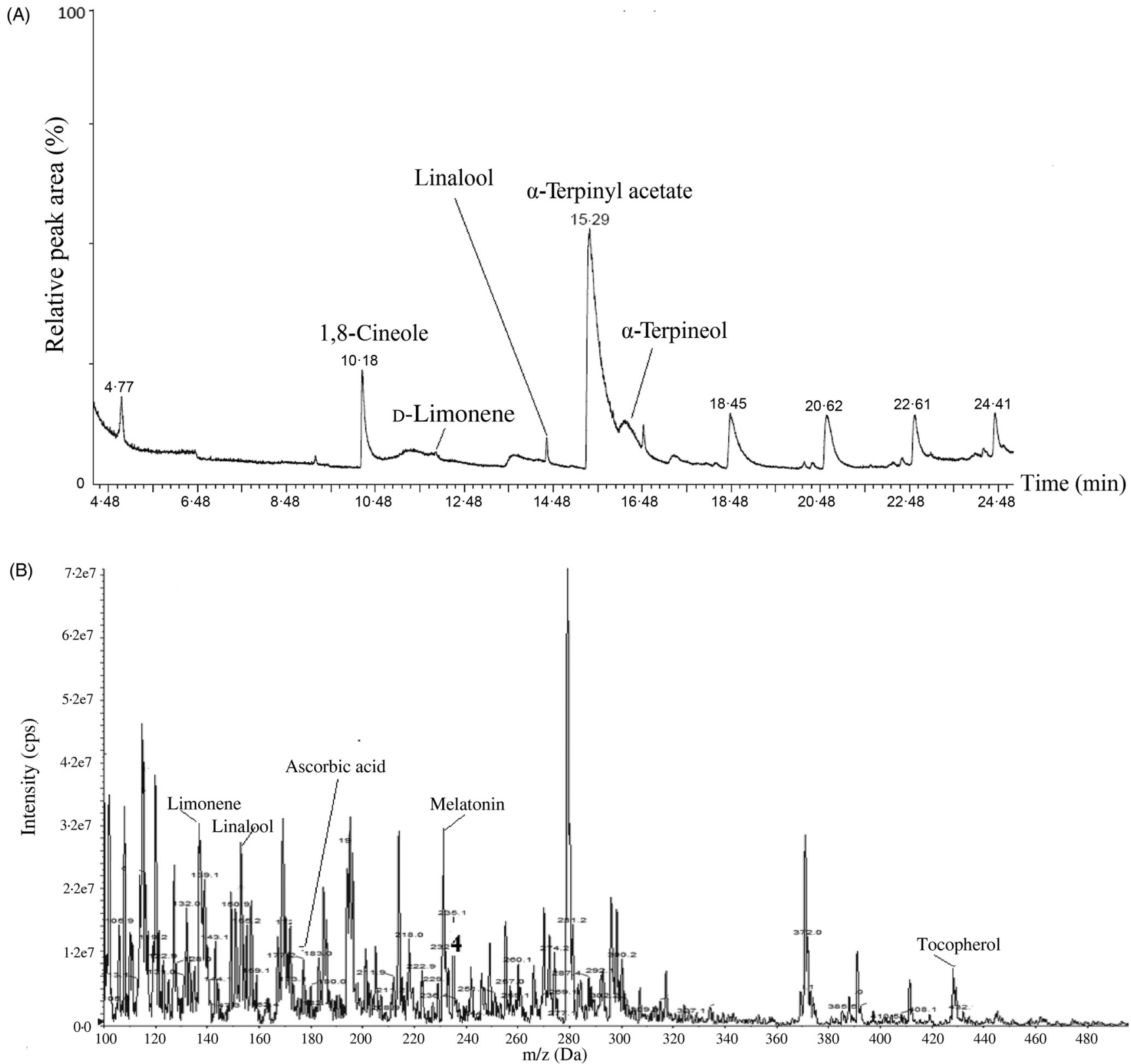

Fig. 5. (A) GC-MS chromatogram of supercritical carbon dioxide $\left(\mathrm{SC}-\mathrm{CO}_{2}\right)$ extract of small cardamom seeds and (B) liquid chromatography-MS chromatogram of $\mathrm{SC}-\mathrm{CO}_{2}$ extract of yellow mustard seeds. cps, Counts per s. 


\section{Acute toxicities of Triton X-100 and supercritical carbon dioxide extracts}

The wellness parameters of rats are presented in Supplementary Table S1. Mortality was found in two rats treated with Triton X-100 (2000 mg/kg BW) within $24 \mathrm{~h}$; however, the remaining three rats were without any signs of toxicity up to $48 \mathrm{~h}$ of dose administration.

The rats administered with $\mathrm{YM}_{\text {best }}$ and $\mathrm{SC}_{\text {best }}$ extracts (5000 $\mathrm{mg} / \mathrm{kg} \mathrm{BW}$ ) did not show any sign of toxicity, such as salivation, lethargy, convulsions, tremors and diarrhoea within $48 \mathrm{~h}$ of dose administration (Supplementary Tables S2 and S3). Therefore, the $\mathrm{LD}_{50}$ value of Triton X-100 was below 2000 $\mathrm{mg} / \mathrm{kg} \mathrm{BW}$, whereas the same for $\mathrm{SC}-\mathrm{CO}_{2}$ extracts were greater than $5000 \mathrm{mg} / \mathrm{kg} \mathrm{BW}$.

\section{Standardised dose of Triton X-100 for inducing hypercholesterolaemia}

Administration of Triton X-100 at multiple doses for 3 consecutive days did not result in a stable serum TC level (Supplementary Fig. S1). In addition, it led to severe structural deterioration in liver and kidney cells, such as damaged glomeruli and dilated renal tubules which in turn impede cholesterol biosynthesis in liver. Similar deterioration in the structure of kidneys was also observed in a toxicity study on acetaminophen $^{(32)}$.
However, a single dose of Triton X-100 (175 mg/kg BW) could maintain a stable hypercholesterolaemic condition without any significant histological alteration (in the structure of kidney and liver cells) after $72 \mathrm{~h}$ of administration. Therefore, based on serum TC level and histological studies, a single dose of $175 \mathrm{mg} / \mathrm{kg} \mathrm{BW}$ of Triton X-100 was considered to be the optimised dose for inducing hypercholesterolaemia in rats.

\section{In vivo efficacies of $S C_{\text {best }}$ and $Y M_{\text {best }}$ on hypercholesterolaemic rats}

Effects on serum total cholesterol levels. The effects of $\mathrm{SC}_{\mathrm{best}}$ and $\mathrm{YM}_{\text {best }}$ on serum TC levels of rats are shown in Fig. 6. Among three different doses $(55,175,550 \mathrm{mg} / \mathrm{kg} \mathrm{BW})$ of extracts, the maximum reduction in serum TC level (49.44 (SD $3.30) \%$ and $48.95(\mathrm{SD} 2.50) \%$ by $\mathrm{YM}_{\text {best }}$ and $\mathrm{SC}_{\text {best }}$, respectively) was found at $550 \mathrm{mg} / \mathrm{kg} \mathrm{BW}$ on day 15. Further feeding of either extract up to day 21 did not cause any significant $(P=0.000$ in either case) change in serum TC level. Percentage reduction in serum TC level was maximum in atorvastatin $(51.26(\mathrm{SD} 4.30) \%)$ treated rats, which corroborated well with the findings of Pasha ${ }^{(53)}$. No adverse effects in the animals were found during the experimental period.

Effect on serum TAG levels. Administration of $\mathrm{YM}_{\text {best }}$ and $\mathrm{SC}_{\text {best }}$ at $550 \mathrm{mg} / \mathrm{kg} \mathrm{BW}$ and atorvastatin $(10 \mathrm{mg} / \mathrm{kg} \mathrm{BW})$ individually resulted in significant lowering $(P=0.000$ in all
(A)
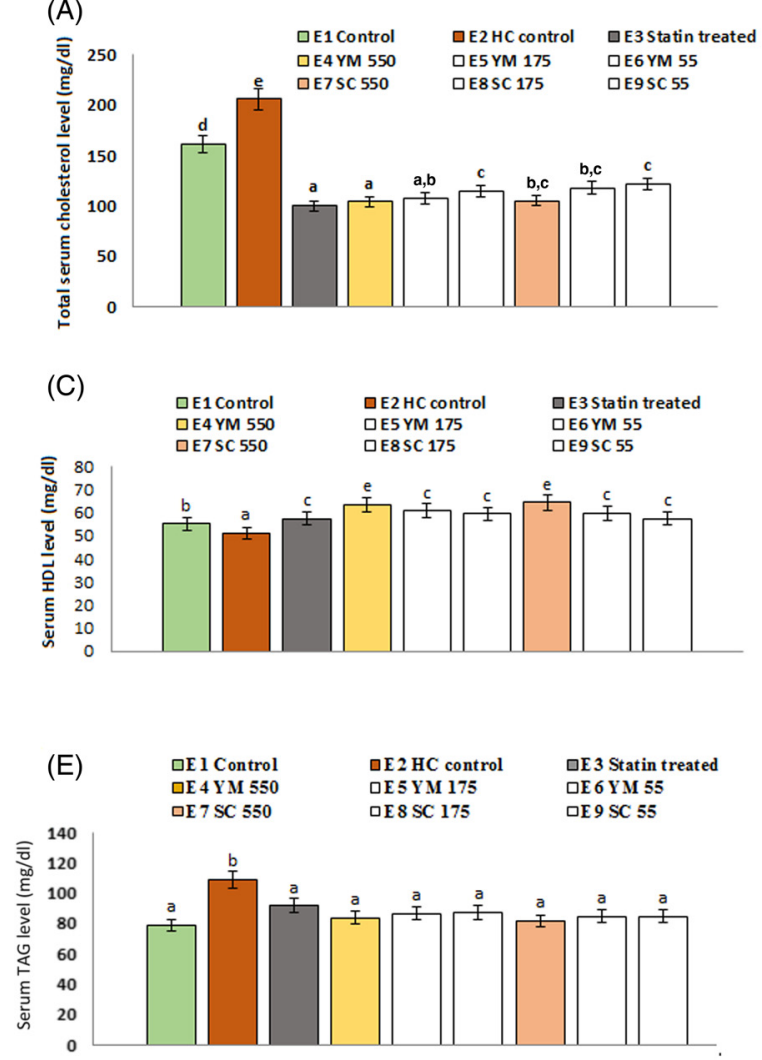
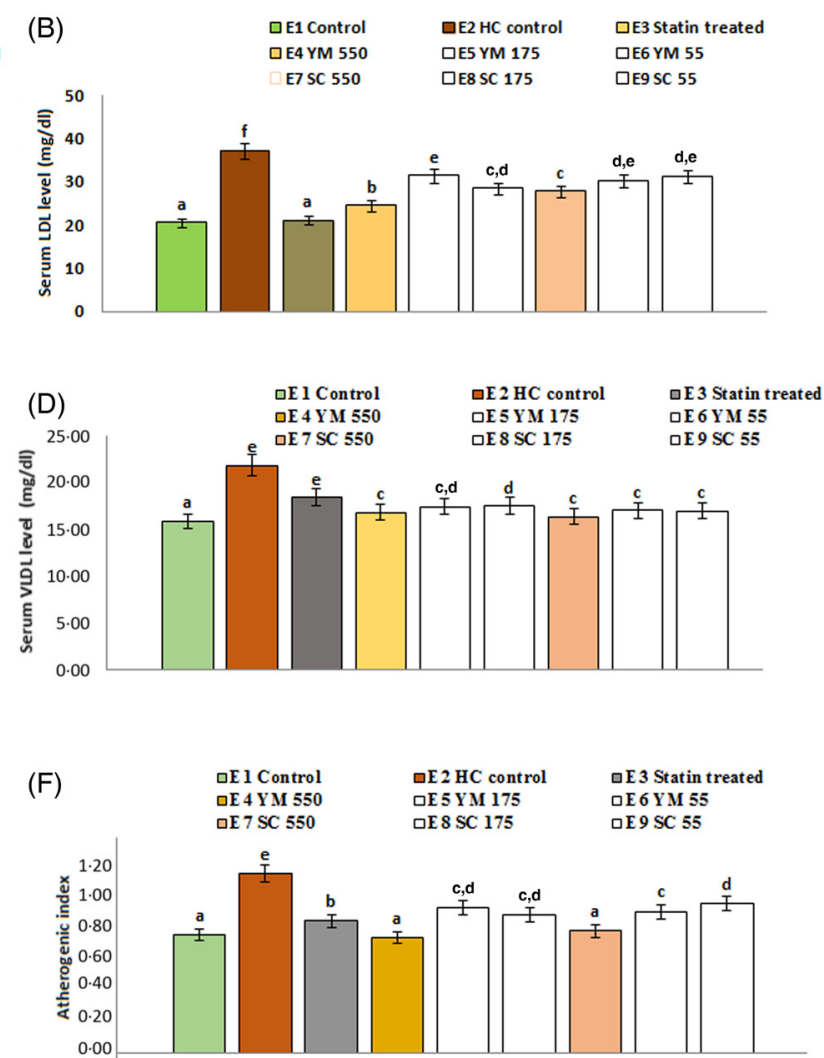

Fig. 6. Effects of supercritical carbon dioxide extracts of yellow mustard (YM) and small cardamom (SC) seeds on lipid profiles of Wistar albino rats. Values are means, with standard deviations represented by vertical bars. ${ }^{a, b, c, d}$ Mean values with unlike letters were significantly different $(P<0.05$; Duncan's multiple-range test). To convert cholesterol in $\mathrm{mg} / \mathrm{dl}$ to $\mathrm{mmol} / \mathrm{l}$, multiply by 0.0259 . To convert TAG in $\mathrm{mg} / \mathrm{dl}$ to $\mathrm{mmol} / \mathrm{l}$, multiply by 0.0113 . 
the cases) of serum TAG levels compared with those in healthy control rats (Fig. 6) on day 21. The decrease in TAG levels of $\mathrm{YM}_{\text {best }}\left(22 \cdot 89\right.$ (SD 2.58( \%) and $\mathrm{SC}_{\text {best }}(25 \cdot 15$ $(\mathrm{SD} 1.11) \%$ ) treated rats were found to be higher than atorvastatin-treated rats $(15.74(\mathrm{sD} 1.04) \%)$.

Effects on serum HDL-cholesterol, LDL-cholesterol and VLDL-cholesterol levels and atherogenic index values. The rats treated with $\mathrm{YM}_{\text {best }}$ and $\mathrm{SC}_{\text {best }}$ (groups $\mathrm{E}_{4}$ and $\mathrm{E}_{7}$ ) showed significant increases $(P=0.008$ and 0.033 , respectively) in serum mean HDL-C levels with concomitant decreases in serum mean LDL-C $(P=0.000$ in either case) levels compared with those in the control group of rats (group $\mathrm{E}_{2}$ ) on day 21 (Fig. 6). Additionally, the serum mean VLDL-cholesterol levels $(0.48 \mathrm{mmol} / \mathrm{l} ; 18.37 \mathrm{mg} / \mathrm{dl})$ also decreased on day 21 , in statin- and extract-treated rats $(0.44$ (SD 0.04)-0.42 (SD 0.06) mmol/1; 16.81 (SD 1.45)-16.32 (SD $2.34 \mathrm{mg} / \mathrm{dl})$ compared with those in healthy control rats $(0.57$ $(\mathrm{sD} 0.06) \mathrm{mmol} / \mathrm{l} ; 21.84(\mathrm{sD} 0.36) \mathrm{mg} / \mathrm{dl})$. AI values $(0.99$ (SD $0 \cdot 08)$ ) of healthy control rats were significantly higher $(P=$ $0.000)$ than those of the extract $(0.68(\mathrm{SD} 0.03)$ to 0.80 (SD 0.05)) and atorvastatin-treated $(0.69(\mathrm{sD} 0.05))$ rats (Fig. 6).

Effects on serum total cholesterol levels after discontinuation of administration of supercritical carbon dioxide extracts.

Rats of group $\mathrm{W}_{1 \mathrm{~A}}$ and $\mathrm{W}_{1 \mathrm{~B}}\left(\mathrm{YM}_{\text {best }}\right.$ treated $)$ showed mean serum TC levels of 0.48 (SD 0.13$) \mathrm{mmol} / 1$ (104.28 (SD
$5.00) \mathrm{mg} / \mathrm{dl}$ ) and 2.97 (SD 0.18$) \mathrm{mmol} / \mathrm{l}(114.56$ (sD 6.96 $\mathrm{mg} / \mathrm{dl}$ ), respectively. The rats of $\mathrm{W}_{2 \mathrm{~A}}$ and $\mathrm{W}_{2 \mathrm{~B}}\left(\mathrm{SC}_{\text {best }}\right.$ treated) showed serum TC levels of 2.80 (SD 0.13 ) $\mathrm{mmol} / 1$ $(108.29(\mathrm{sD} 4.89) \mathrm{mg} / \mathrm{dl})$ and $3.07 \quad(\mathrm{SD} \quad 0.17) \mathrm{mmol} / \mathrm{l}$ $(118.34(\mathrm{SD} 6.65) \mathrm{mg} / \mathrm{dl}$ ), respectively (Fig. 7). In both cases, the differences between the serum TC levels of treatment continued and discontinued groups were insignificant $(P=$ 0.041 for $\mathrm{YM}_{\text {best }}$-administered rats; $P=0.022$ for $\mathrm{SC}_{\mathrm{best}^{-}}$ administered rats) on day 21 . The present study conclusively suggests that the extracts could be served for $15 \mathrm{~d}$ at a dose of $550 \mathrm{mg} / \mathrm{kg}$ BW to achieve a normal serum TC level in hypercholesterolaemic rats.

Effects on hepatic 3-hydroxy-3-methyl-glutaryl-COA reductase activity. On day 21, hepatic HMG-CoA:mevalonate ratios also increased in $\mathrm{YM}_{\text {best }}\left(2 \cdot 70\right.$ (SD 0.12)), $\mathrm{SC}_{\text {best, }}(2 \cdot 76$ (SD 0.19)) and atorvastatin $(2.86(\mathrm{SD} 0.32))$ treated rats than those of healthy control rats $(2.33$ (SD 0.09)) (Table 1), indicating possible enzyme-inhibitory effect of the extracts.

Histological changes and effects on liver and kidney markers. The microscopic images of livers and kidneys are presented in Figs $8((\mathrm{~A})-(\mathrm{D}))$ and $9((\mathrm{~A})-(\mathrm{D}))$, respectively. There were significant changes in kidneys and livers of the Triton X-100-treated rats (175 mg/kg BW) on day 21. The liver of the extract-administered rats exhibited normal structure of central vein and hepatic cords (Fig. 8). Histological
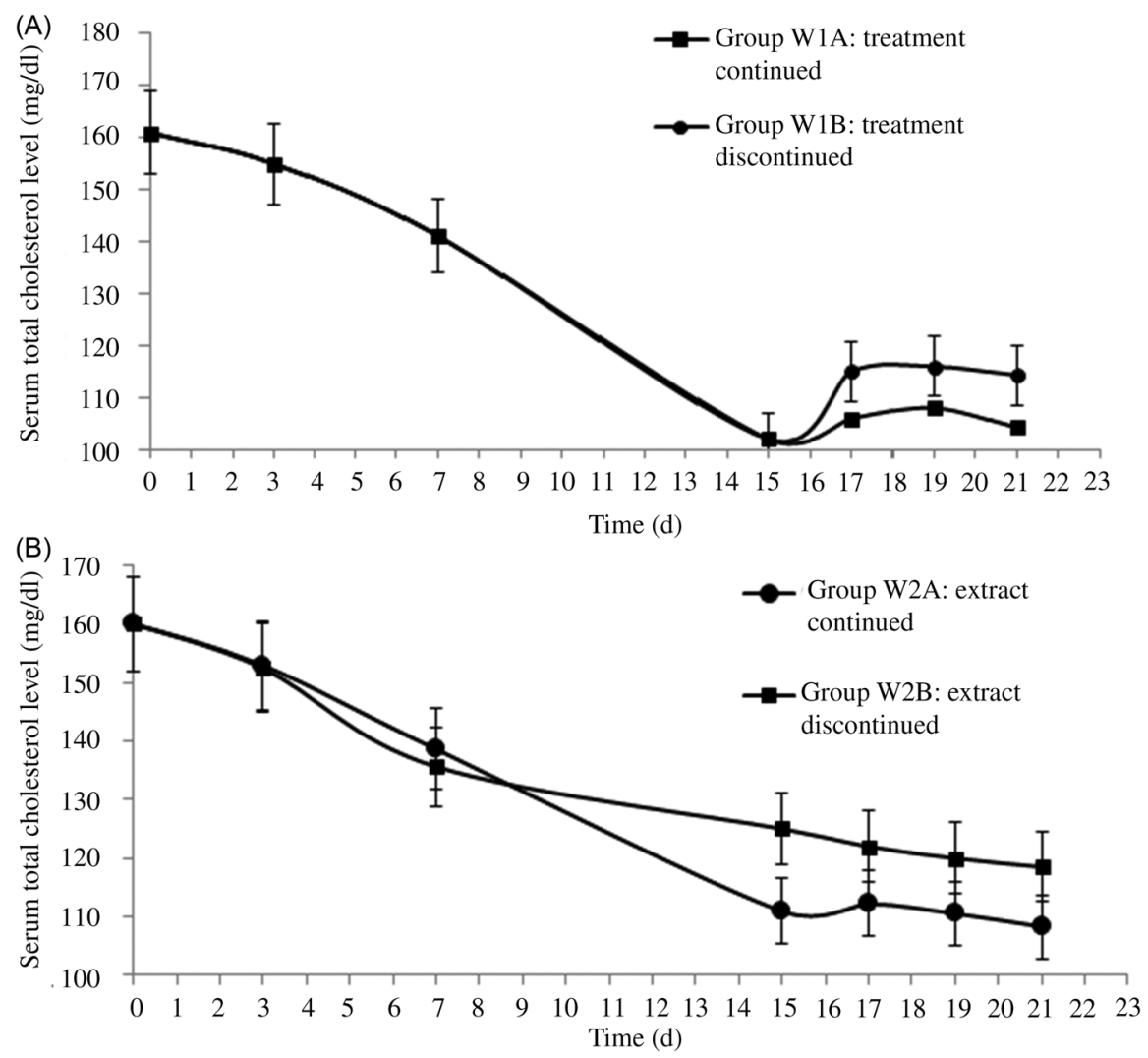

Fig. 7. Serum cholesterol levels after discontinuation of treatment with (A) yellow mustard seed extract and (B) small cardamom seed extract. Values are means, with standard deviations represented by vertical bars. To convert cholesterol in $\mathrm{mg} / \mathrm{dl}$ to $\mathrm{mmol} / \mathrm{l}$, multiply by 0.0259 . 
Table 1. Effect of supercritical carbon dioxide extracts of yellow mustard seeds and small cardamom seeds on 3-hydroxy-3-methyl-glutaryl-CoA: mevalonate (H:M) ratio, kidney and liver markers in hypercholesterolaemic rats

(Mean values and standard deviations; six rats per group)

\begin{tabular}{|c|c|c|c|c|c|c|c|c|c|c|c|c|c|}
\hline \multirow[b]{2}{*}{ Groups } & \multirow[b]{2}{*}{ Description of animal groups } & \multicolumn{2}{|c|}{ H:M ratio } & \multicolumn{2}{|c|}{$\begin{array}{l}\text { BUN } \\
(\mathrm{mg} / \mathrm{dl})^{*}\end{array}$} & \multicolumn{2}{|c|}{$\begin{array}{l}\text { Creatinine } \\
(\mathrm{mg} / \mathrm{dl})^{*}\end{array}$} & \multicolumn{2}{|c|}{$\begin{array}{l}\text { Urea } \\
(\mathrm{mg} / \mathrm{dl})^{\star}\end{array}$} & \multicolumn{2}{|c|}{ SGOT (IU/I) } & \multicolumn{2}{|c|}{ SGPT (IU/l) } \\
\hline & & Mean & SD & Mean & SD & Mean & SD & Mean & SD & Mean & SD & Mean & SD \\
\hline$E_{1}$ & $\begin{array}{l}\text { Regular oral administration of } 10 \% \text { DMSO solution } \\
\text { for } 21 \mathrm{~d}\end{array}$ & $2.95^{\mathrm{a}}$ & 0.12 & $18 \cdot 01^{\mathrm{a}}$ & 0.91 & $0.60^{\mathrm{a}}$ & 0.02 & $33.29^{a}$ & 1.33 & $40 \cdot 78^{a}$ & $2 \cdot 11$ & $40 \cdot 00^{\mathrm{a}}$ & $2 \cdot 11$ \\
\hline $\mathrm{E}_{2}$ & $\begin{array}{l}\text { Injected intraperitoneally with single dose of Triton X-100 } \\
(175 \mathrm{mg} / \mathrm{kg} \text { BW) on day } 1 \text { and regular oral } \\
\text { administration of } 10 \% \text { DMSO solution for } 21 \mathrm{~d}\end{array}$ & $2 \cdot 33^{b}$ & 0.09 & $23.00^{\mathrm{b}}$ & 0.88 & $0.97^{b}$ & 0.03 & $67 \cdot 19^{b}$ & $2 \cdot 31$ & $89.47^{b}$ & 1.99 & $51 \cdot 25^{\mathrm{b}}$ & 1.99 \\
\hline$E_{3}$ & $\begin{array}{l}\text { Injected intraperitoneally with single dose of Triton X-100 } \\
(175 \mathrm{mg} / \mathrm{kg} \mathrm{BW}) \text { on day } 1 \text { and oral administration of } \\
\text { atorvastatin } 10 \mathrm{mg} / \mathrm{kg} \mathrm{BW} \text { for } 21 \mathrm{~d}\end{array}$ & $2 \cdot 86^{a}$ & 0.32 & $18 \cdot 21^{\mathrm{a}}$ & 0.98 & $0.75^{\mathrm{c}}$ & 0.03 & $35 \cdot 26^{a}$ & 1.88 & $42 \cdot 45^{\mathrm{a}}$ & 5.01 & $39.20^{\mathrm{a}}$ & 5.01 \\
\hline $\mathrm{E}_{4}$ & $\begin{array}{l}\text { Injected intraperitoneally with single dose of Triton X-100 } \\
(175 \mathrm{mg} / \mathrm{kg} \mathrm{BW}) \text { on day } 1 \mathrm{and} \text { oral administration of } \\
\mathrm{YM}_{\text {best }} \text { at the dose of } 550 \mathrm{mg} / \mathrm{kg} \mathrm{BW} \text { for } 21 \mathrm{~d}\end{array}$ & $2 \cdot 42^{\mathrm{c}}$ & 0.11 & $19 \cdot 45^{\mathrm{a}}$ & 0.89 & $0.78^{\mathrm{c}}$ & 0.01 & $41 \cdot 25^{\mathrm{C}}$ & 1.71 & $45 \cdot 02^{a}$ & 4.89 & $39.50^{a}$ & 4.89 \\
\hline$E_{5}$ & $\begin{array}{l}\text { Injected intraperitoneally with single dose of Triton X-100 } \\
(175 \mathrm{mg} / \mathrm{kg} \mathrm{BW}) \text { on day } 1 \text { and oral administration of } \\
\mathrm{YM}_{\text {best }} \text { at the dose of } 175 \mathrm{mg} / \mathrm{kg} \mathrm{BW} \text { for } 21 \mathrm{~d}\end{array}$ & $2.42^{\mathrm{d}}$ & 0.15 & $22 \cdot 08^{\mathrm{a}}$ & 0.92 & $0.88^{\mathrm{C}}$ & 0.04 & $50 \cdot 00^{\mathrm{d}}$ & 2.05 & $46 \cdot 69^{a}$ & 6.88 & $42 \cdot 29^{a}$ & 6.88 \\
\hline $\mathrm{E}_{6}$ & $\begin{array}{l}\text { Injected intraperitoneally with single dose of Triton X-100 } \\
(175 \mathrm{mg} / \mathrm{kg} \mathrm{BW}) \text { on day } 1 \text { and oral administration of } \\
\mathrm{YM}_{\text {best }} \text { at the dose of } 55 \mathrm{mg} / \mathrm{kg} \mathrm{BW} \text { for } 21 \mathrm{~d}\end{array}$ & $2 \cdot 70^{\mathrm{d}}$ & 0.12 & $20 \cdot 02^{a}$ & 0.99 & $0.92^{b}$ & 0.05 & $61.66^{\mathrm{d}}$ & 1.98 & $48 \cdot 12^{a}$ & 2.73 & $41 \cdot 36^{\mathrm{a}}$ & 2.73 \\
\hline$E_{7}$ & $\begin{array}{l}\text { Injected intraperitoneally with single dose of Triton X-100 } \\
(175 \mathrm{mg} / \mathrm{kg} \mathrm{BW} \text { ) on day } 1 \text { and oral administration of } \\
\mathrm{SC}_{\text {best }} \text { at the dose of } 550 \mathrm{mg} / \mathrm{kg} \mathrm{BW} \text { for } 21 \mathrm{~d}\end{array}$ & $2.55^{\mathrm{C}}$ & 0.16 & $19.00^{a}$ & 0.83 & $0.85^{\mathrm{c}}$ & 0.04 & $40 \cdot 23^{c}$ & 1.59 & $44 \cdot 14^{a}$ & 4.56 & $40.05^{a}$ & 4.56 \\
\hline$E_{8}$ & $\begin{array}{l}\text { Injected intraperitoneally with single dose of Triton X-100 } \\
\text { ( } 175 \mathrm{mg} / \mathrm{kg} \mathrm{BW} \text { ) on day } 1 \text { and oral administration of } \\
\mathrm{SC}_{\text {best }} \text { at the dose of } 175 \mathrm{mg} / \mathrm{kg} \mathrm{BW} \text { for } 21 \mathrm{~d}\end{array}$ & $2.66^{d}$ & 0.08 & $21.02^{\mathrm{a}}$ & 0.94 & $0.81^{c}$ & 0.03 & $51.44^{d}$ & $2 \cdot 13$ & $46 \cdot 08^{a}$ & 6.32 & $42 \cdot 85^{a}$ & $6 \cdot 32$ \\
\hline$E_{9}$ & $\begin{array}{l}\text { Injected intraperitoneally with single dose of Triton X-100 } \\
(175 \mathrm{mg} / \mathrm{kg} \mathrm{BW} \text { ) on day } 1 \text { and oral administration of } \\
\mathrm{SC}_{\text {best }} \text { at the dose of } 55 \mathrm{mg} / \mathrm{kg} \mathrm{BW} \text { for } 21 \mathrm{~d}\end{array}$ & $2 \cdot 76^{\mathrm{C}}$ & 0.19 & $20 \cdot 00^{\mathrm{a}}$ & 0.89 & $0.83^{\mathrm{c}}$ & 0.05 & $63.04^{d}$ & 1.34 & $48.99^{a}$ & $2 \cdot 18$ & $42 \cdot 77^{\mathrm{a}}$ & $2 \cdot 18$ \\
\hline
\end{tabular}

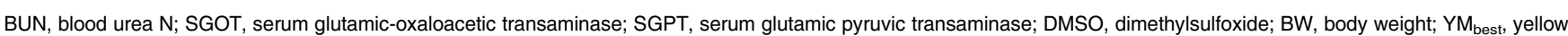
mustard seed extract obtained at the optimum conditions of supercritical $\mathrm{CO}_{2} ; \mathrm{SC}_{\text {best }}$, small cardamom seed extract obtained at the optimum conditions of supercritical $\mathrm{CO}_{2}$.

a,b,c,d Mean values within a column with unlike superscript letters were significantly different $(P<0.05$; Duncan's multiple-range test).

* To convert BUN from $\mathrm{mg} / \mathrm{dl}$ to $\mathrm{mmol} / \mathrm{l}$, multiply by 0.357 . To convert creatinine from $\mathrm{mg} / \mathrm{dl}$ to $\mu \mathrm{mol} / \mathrm{l}$, multiply by 88.4 . To convert urea from mg/dl to $\mathrm{mmol} / \mathrm{l}$, multiply by $0 \cdot 1665$.

structures of kidneys of the hypocholesterolaemic control group (group $\mathrm{E}_{2}$ ) of rats showed severe disorganisation of the glomerulus and dilation of renal tubules; however, kidneys of extract-administered rats showed no such morphological aberrations (Fig. 9).

The levels of serum BUN (blood urea N), urea and creatinine (liver markers), serum SGPT (serum glutamic pyruvic transaminase) and SGOT (serum glutamic-oxaloacetic transaminase) (kidney markers) levels of the rats are presented in Table 1. No alternations in serum urea and creatinine levels were observed in the rats treated with atorvastatin and $\mathrm{YM}_{\text {best }}$ and $\mathrm{SC}_{\text {best }}$ during the experimental period of $21 \mathrm{~d}$; however, the levels changed significantly $(P=0 \cdot 000)$ in the healthy control (group $E_{2}$ ) rats. Considering the animal dose to be 550
(A)

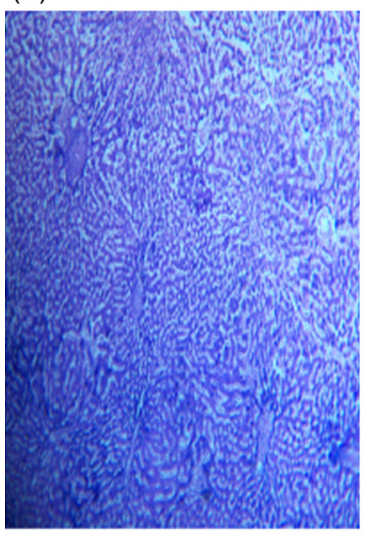

(B)

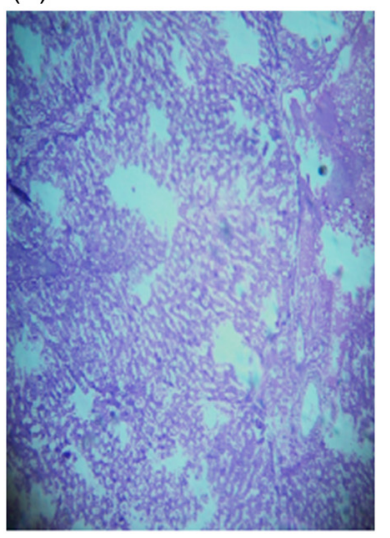

(C)

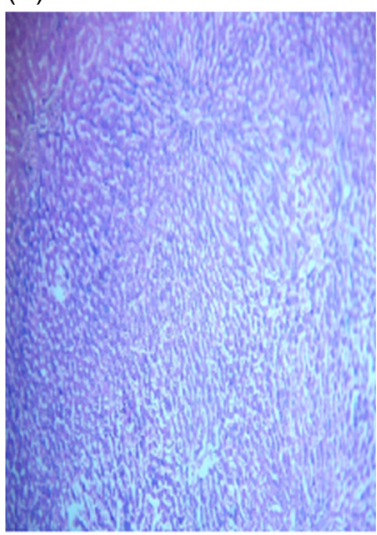

(D)

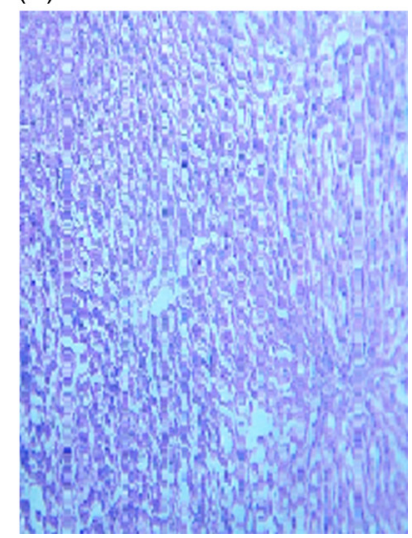

Fig. 8. Histology of liver of $(A)$ control group of rats showing well-organised lobular structure, (B) group of rats treated with optimised dose of Triton $\mathrm{X}-100$ (175 mg/kg body weight $(B W)$ ) showing disorganised structure of liver, $(C)$ rats treated with yellow mustard seed extract (550 mg/kg BW) and (D) small cardamom seed extract $(550 \mathrm{mg} / \mathrm{kg} \mathrm{BW})$ showing organised structure of hepatic lobules. 
(A)

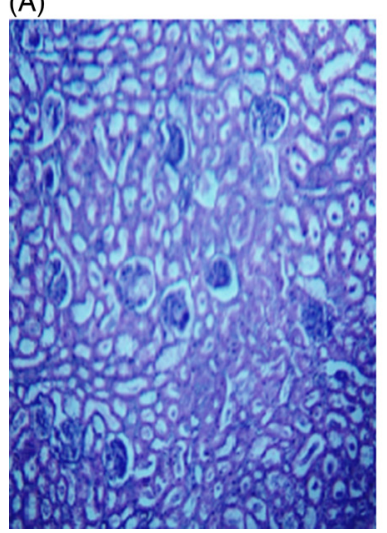

(B)

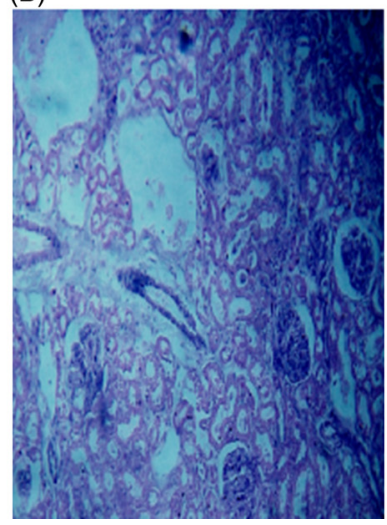

(C)

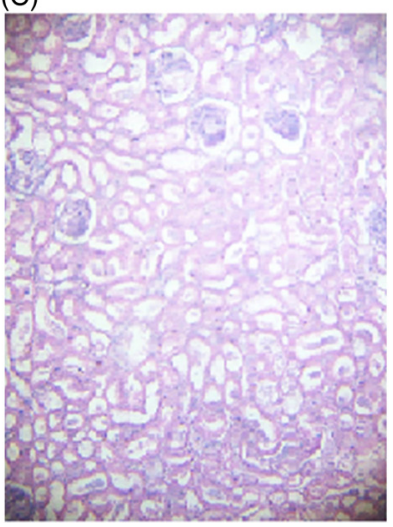

(D)

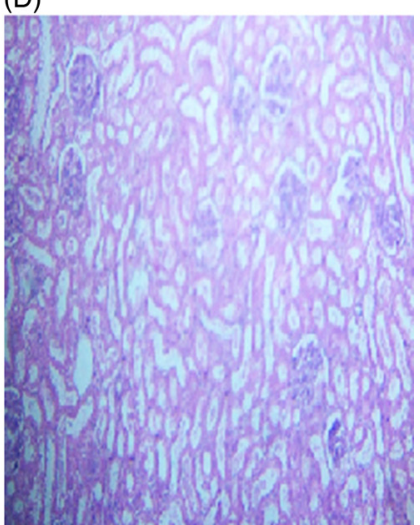

Fig. 9. Histology of kidney of (A) control group of rats showing normal renal tubules with intact well-organised cellular boundary, (B) rats treated with multiple doses of Triton X-100 (175 mg/kg body weight (BW)) showing severe disorganisation in the renal tubules, (C) rats treated with yellow mustard seed extract (550 mg/kg BW) and (D) small cardamom seed extract $(550 \mathrm{mg} / \mathrm{kg} \mathrm{BW})$ showing normal organisation in the renal tubules.

$\mathrm{mg} / \mathrm{kg} \mathrm{BW}$ at which no adverse effects in the animals were found, HED was calculated to be $89 \mathrm{mg} / \mathrm{kg}$ BW for $\mathrm{SC}_{\text {best }}$ and $\mathrm{YM}_{\text {best }}$.

\section{Docking scores of extract components with}

\section{3-hydroxy-3-methyl-glutaryl-CoA reductase}

Fig. 7 provides the docking scores of $\alpha$-terpinyl acetate, $\alpha$-terpineol, limonene, linalool and 1,8-cineole with respect to the bound substrate (HMG-CoA) and inhibitors (statins) of $\mathrm{HMG}-\mathrm{CoA}$ receptor protein. Ingredient molecules were docked at the statin binding site (Fig. 10(A)) of HMG-CoA receptor using the GOLD package ${ }^{(43)}$. Average docking scores of the top three scoring solutions (pose) from the largest cluster of each active ingredient molecules were calculated and compared against GOLD-generated rescores derived from the substrate (HMG-CoA) and inhibitors (statins) bound to HMG-CoA receptor protein structures (Fig. 10(B)). Fig. 10 (C) and 10(D) provide the LigPlot representation of the interacting residues and the probable interaction types for one of the known inhibitors (atorvastatin) and the highest scoring active ingredient (linalool), respectively.

The docking exercise at the statin-binding site of HMG-CoA reductase suggested that linalool and $\alpha$-terpineol achieve docking scores comparable with therapeutically used HMG-CoA reductase inhibitors. However, the size and
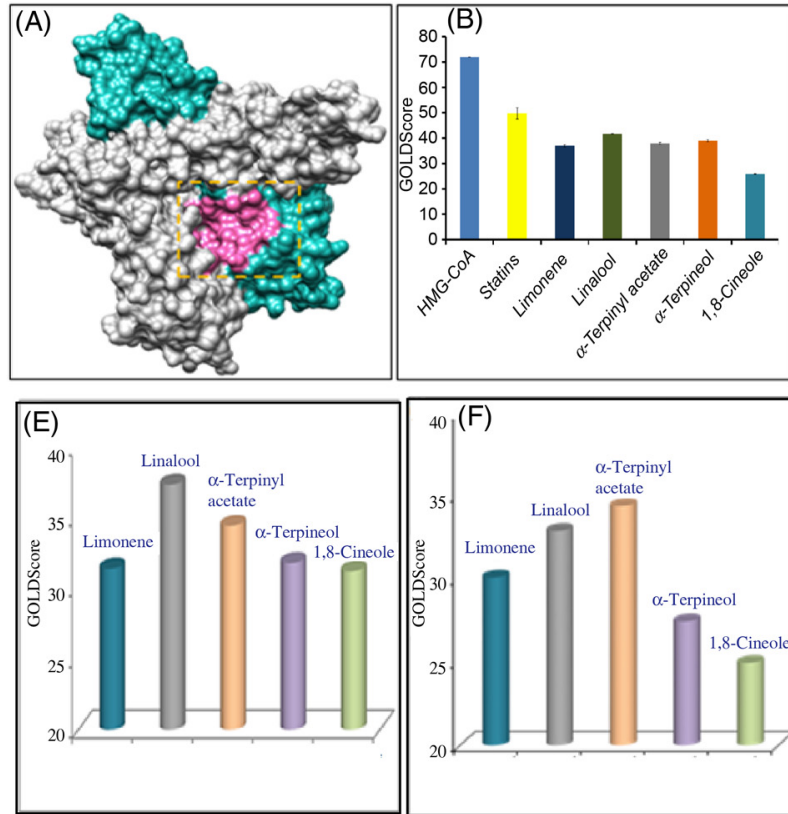
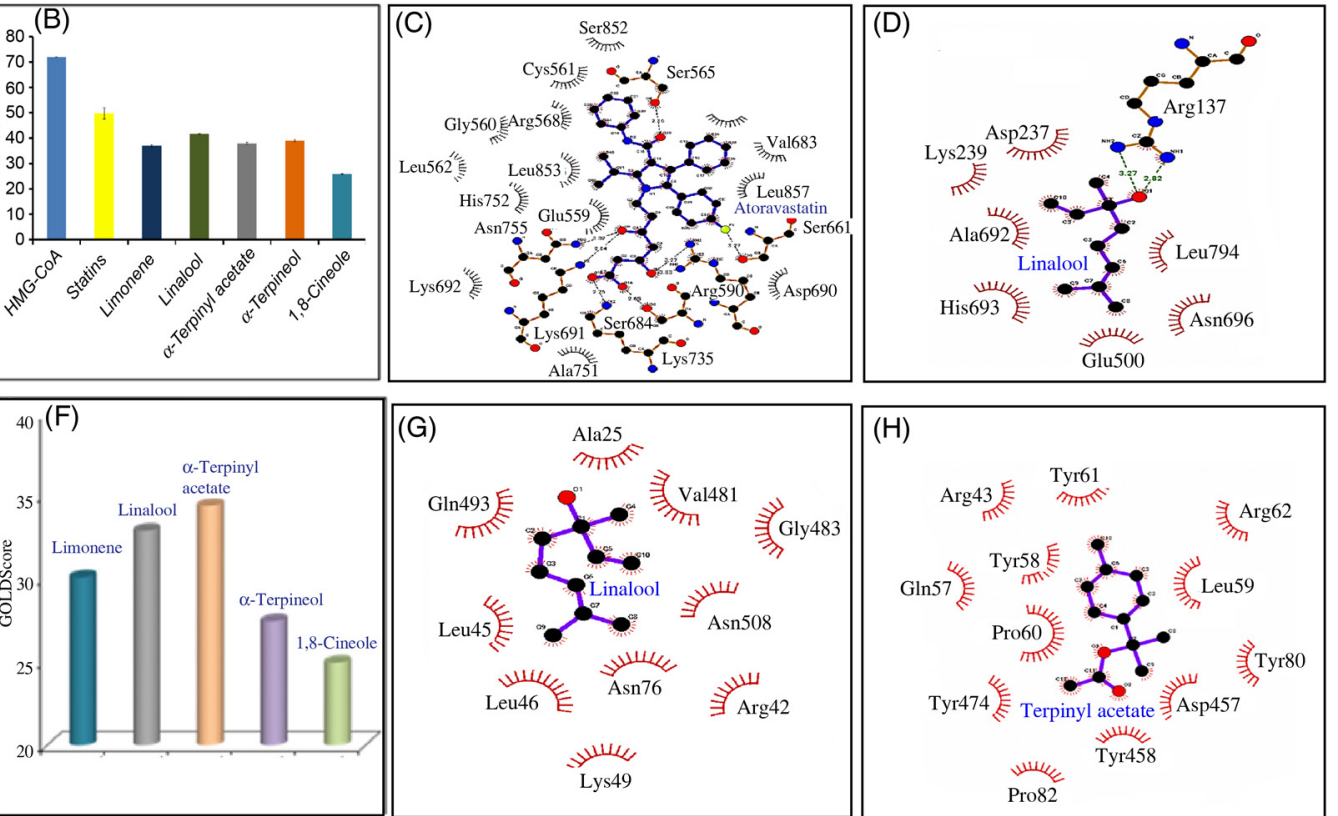

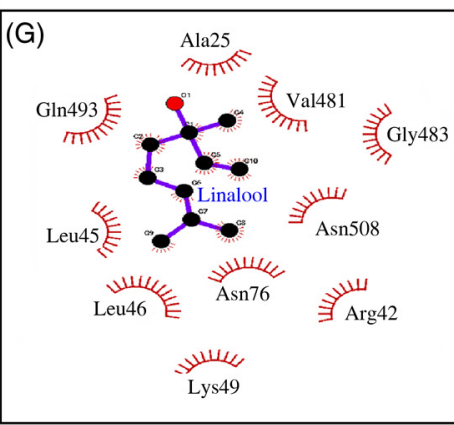

$(\mathrm{H})$

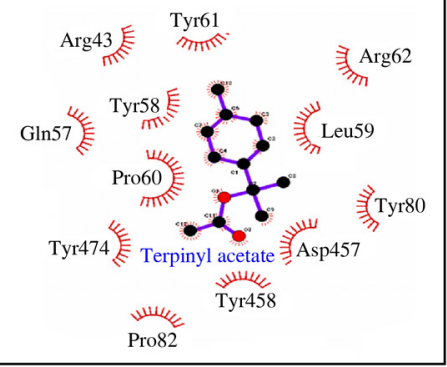

Fig. 10. (A) Three-dimensional surface view of one of the dimer structures of 3-hydroxy-3-methyl-glutaryl-CoA (HMG-CoA) receptor (Protein Data Bank ID: 1HWK) where two chains are marked in grey and cyan and the substrate/inhibitor binding pocket is shown in pink. (B) Average molecular docking score represented as GOLDScore is plotted for each active ingredient of the cardamom extract when docked at the substrate/inhibitor binding site. GOLD derived rescores of the substrate (HMG-CoA) and inhibitors (statins) bound to HMG-CoA receptor protein are also plotted for comparison purposes. Values are means, with standard deviations represented by vertical bars. (C, D) LigPlot representations of the interacting residues and the probable interaction types for one of the known inhibitor (atorvastatin) and the highest-scoring active ingredient (linalool), respectively. (E, F) Average molecular docking scores represented as GOLDScore are plotted for each active ingredient of the cardamom extract when docked at the predicted binding sites, consensus pocket 2 and 3 , respectively. (G, H) LigPlot representations of the interacting residues and the probable interaction types derived from linalool and $\alpha$-terpinyl acetate docked at the predicted binding sites, consensus pocket 2 and 3 , respectively. 
surface area of the active molecules are considerably smaller than the substrate HMG-CoA and the statins (Supplementary Fig. S2). Hence, they do not occupy the full substrate/inhibitor binding pocket, and instead bind to subpockets within the substrate/statin binding pocket.

The possibility of binding to other probable cavity/pockets was also explored via the prediction of pockets and subsequent docking to those pockets. Two such pockets were identified that were commonly predicted by two programs (Fig. S3). Each active ingredient was docked onto all these pockets and docking scores of the most likely solutions were plotted (Fig. 10(E) and $10(\mathrm{~F}))$ and the ligand-protein interactions were identified by the LigPlot program (Fig. 10(G) and 10(H)). The docking exercise at those pockets also suggested that linalool and $\alpha$-terpinyl acetate possess higher docking probabilities.

\section{Discussion}

Antioxidant synergy by reductionism

The green extraction technology of $\mathrm{SC}-\mathrm{CO}_{2}$ has delivered 'melatonin-rich $\mathrm{YM}_{\text {best }}$ ' and '1,8-cineole-rich $\mathrm{SC}_{\text {best }}$ ' extracts from YM and SC seeds, respectively. Although reductionism through $\mathrm{SC}-\mathrm{CO}_{2}$ extraction was conducted using statistical design models and analytical tools, chemical profiling and determination of SE values revealed a synergistic consortium of antioxidants in either extract, and not melatonin and 1,8-cineole as isolated single antioxidants. The present study established methodological reductionism as a successful approach to obtain consortia of bioactives from plant parts which exhibited antioxidant synergies. These synergistic consortia of antioxidants in the spices could reduce in vivo lipid peroxidation rate, restore antioxidant activity and delay the development of hypercholesterolaemia ${ }^{(54)}$ in animals, rendering the extracts suitable for in vivo investigation in redressing this oxidative stress disorder ${ }^{(55)}$.

\section{In vivo efficacies of the supercritical carbon dioxide extracts}

Co-administration of $\mathrm{YM}_{\text {best }}$ and $\mathrm{SC}_{\text {best }}$ at a dose of $550 \mathrm{mg} /$ $\mathrm{kg} \mathrm{BW}$ for $15 \mathrm{~d}$ along with a single dose $(175 \mathrm{mg} / \mathrm{kg} \mathrm{BW})$ of Triton X-100 resulted in the maximum reduction of serum TC levels. Hussain ${ }^{(56)}$ had reported a $13.75 \%$ reduction in the serum TC level of hypercholesterolaemic Sprague-Dawley rats, treated with standard melatonin $(10 \mathrm{mg} / \mathrm{kg})$ for $30 \mathrm{~d}$. However, a higher hypocholesterolaemic efficacy of $\mathrm{YM}_{\text {best }}$ extract has been established in the present study compared with those treated with whole mustard seeds $(14.90 \%$ after $90 \mathrm{~d})^{(16)}$. Similarly, the rats treated with $\mathrm{SC}_{\text {best }}$ also exhibited a higher reduction in serum TC level than those reported by Nagashree $e t a l .{ }^{(17)}$ for SC seed oil (31\% reduction at a dose of $3 \mathrm{~g} / \mathrm{kg} \mathrm{BW}$ after 8 weeks). Therefore, it could be reasonably concluded that the strong hypocholesterolaemic activities of $\mathrm{SC}_{\text {best }}$ and $\mathrm{YM}_{\text {best }}$ were not owing to their respective bioactive principles alone but rather due to the consortia of bioactives therein. Moreover, administration of extracts also improved the serum TAG as well as lipoprotein levels (increase in HDL-C and decrease in LDL-C).
The HED of $\mathrm{SC}_{\text {best }}$ was found to be $89 \mathrm{mg} / \mathrm{kg} \mathrm{BW}$, which is higher than the reported dose $(50 \mathrm{mg} / \mathrm{kg} \mathrm{BW})$ of whole cardamom (variety not reported) in clinical studies ${ }^{(3,4)}$. Since $\mathrm{SC}_{\text {best }}$ and $\mathrm{YM}_{\text {best }}$ are non-toxic and safe for consumption, either extract can be subjected to clinical trials at a HED of $89 \mathrm{mg} / \mathrm{kg} \mathrm{BW}$.

\section{Inhibitory effects of extract components on 3-hydroxy-3-methyl-glutaryl-CoA reductase in terms of docking scores}

The inhibitory effects of the extracts on hepatic HMG-CoA reductase activities possibly contributed to the maintenance of normal serum TC and lipoprotein levels in hypercholesterolaemic rats. Molecular docking results revealed that linalool achieved the highest docking scores in the statin-bound site, suggesting its strong inhibitory action on HMG-CoA reductase. Both extracts therefore exhibited their inhibitory effects on hepatic HMG-CoA reductase activities owing to the presence of linalool therein. Additionally, $\alpha$-terpineol and $\alpha$-terpinyl acetate of $\mathrm{SC}_{\text {best }}$ are more potent in inhibiting HMG-CoA reductase activity than 1,8-cineole and limonene in terms of their respective docking scores.

Since melatonin has no inhibitory effect on HMG-CoA reductase activity, the docking study suggested that the said activity of the $\mathrm{YM}_{\text {best }}$ extract is conferred possibly by limonene and linalool therein. Additionally, in vivo studies reported by several authors suggested that other major co-extractants of $\mathrm{YM}_{\text {best }}$, namely tocopherol ${ }^{(57)}$, ascorbic acid ${ }^{(58)}$ and MUFA (chiefly arachidic acid, palmitic acid, caproic acid, caprylic acid ${ }^{(59)}$, possess inhibitory efficacies on HMG-CoA reductase activity. Thus, it could be reasonably concluded that all the major co-extractants in $\mathrm{YM}_{\text {best }}$ extract including melatonin contributed in maintaining the serum TC levels by inhibiting HMG-CoA reductase activity.

Although melatonin has no inhibitory effect on HMG-CoA reductase activity, augmenting effects of melatonin on lecithin-cholesterol acyltransferase (LCAT)-mediated cholesterol esterification (leading to increased synthesis of HDL-C) and decreased TC level, have been reported by Esquifino et $a l^{(60)}$. From the above studies, it can be unambiguously concluded that linalool, $\alpha$-terpineol and $\alpha$ - terpinyl acetate in $\mathrm{SC}_{\text {best }}$ and linalool (besides tocopherol, ascorbic and MUFA) in $\mathrm{YM}_{\text {best }}$ inhibited HMG-CoA reductase activity contributing to lowering of serum TC level in rats.

\section{Authentic natural leads and not invalid metabolic panaceas}

It is always important to validate the authenticity of bioactive principles in natural resources prior to designating them as natural leads to avoid invalid metabolic panaceas of the compounds. Although molecular docking of the respective bioactive compounds of both extracts indicated their individual inhibitory effects on HMG-CoA reductase activity, they may not possess the same property when present in combination in the extracts, if they do not act in synergism with other compounds therein. Moreover, they may impede bioactivities of the other co-extractants. In silico molecular docking and in vivo hypocholesterolaemic studies revealed that oral administrations of $\mathrm{YM}_{\text {best }}$ 
and $\mathrm{SC}_{\text {best }}$ inhibited hepatic $\mathrm{HMG-CoA}$ reductase activities and therefore possibly down-regulated de novo cholesterol synthesis in the rats. These biotherapeutic molecules are therefore not invalid metabolic panaceas but authentic natural leads for the design of therapeutic foods and natural product-based drugs.

\section{Conclusion}

In the present study, it can be reasonably concluded that the consortia of bioactives in $\mathrm{YM}_{\text {best }}$ and $\mathrm{SC}_{\text {best }}$ conferred the $\mathrm{SC}-\mathrm{CO}_{2}$ extracts as novel spice-based biotherapeutics in preventing hypercholesterolaemia and therefore cannot be considered as invalid metabolic panaceas. Oral administration of extracts in rats would exhibit dual benefits, namely the inhibition of HMG-CoA reductase activity resulting in the prevention of $d e$ novo cholesterol synthesis, and scavenging of reactive oxygen species leading to reduction of hypercholesterolaemia-induced oxidative stress. These 'green' extracts therefore qualify for human clinical trials and could be safely consumed per se as hypocholesterolaemic supplements. These $\mathrm{SC}-\mathrm{CO}_{2}$ extracts could also be utilised in designing new therapeutic foods for redressing hypercholesterolaemia.

\section{Supplementary materia}

The supplementary material for this article can be found at https://doi.org/10.1017/jns.2019.28

\section{Acknowledgements}

The study has been conducted under the supervision of Dr Paramita Bhattacharjee, Dr Dilip Kumar Nandi, Dr Koushik Das and Dr Saikat Chakrabarti who have contributed to extraction and characterisation, in vivo animal model experiments and molecular docking study, respectively. Soumi Chakraborty, Kaninika Paul, Shrabani Pradhan and Priyanka Mallick are senior research scholars who have conducted the research work. The authors acknowledge Dr Dipan Chatterjee (former Senior Research Scholar, Department of Food Technology and Biochemical Engineering, Jadavpur University, India) for his assistance in the molecular docking study.

The authors are thankful to University Grant Commission (UGC) New Delhi, India (reference no. 1440/(NET-JUNE 2013)) and Spices Board, Cochin, Government of India, for providing financial support for the study.

The authors would like to acknowledge M/s Keva Flavours Pvt Ltd, Mumbai, India for gifting us the pure standards of $\alpha$-terpineol, $\alpha$-terpinyl acetate, linalool and limonene.

The authors declare no conflict of interest.

\section{References}

1. Ghosh S, Bhattacharjee P \& Das S (2015) 1,8-Cineol-rich cardamom seed (Elettaria cardamomum) extracts using green technologies and conventional extractions: process analysis, phytochemical characterization, and food application. Sep Sci Technol 50, 1974-1985.

2. Oram R, Salisbury P, Kirk J, et al. (1999) Brassica juncea Breeding. Canola in Australia: The First Thirty Years. New South Wales: Australian Oil Seed Federation. http://www.australianoilseeds.
com/_data/assets/pdf_file/0016/2707/Chapter_7__Brassica_Juncea_Breeding.pdf (accessed August 2018).

3. Verma SK, Jain V \& Katewa SS (2009) Blood pressure lowering, fibrinolysis enhancing and antioxidant activities of cardamom (Elettaria cardamomum). Indian J Biochem Biophys 46, 503-506.

4. Kazemi S, Yaghooblou F, Siassi F, et al. (2017) Cardamom supplementation improves inflammatory and oxidative stress biomarkers in hyperlipidemic, overweight, and obese pre-diabetic women: a randomized double-blind clinical trial. J Sci Food Agric 97, 52965301

5. Messina M, Lampe JW, Birt DF, et al. (2001) Reductionism and the narrowing nutrition perspective: time for re-evaluation and emphasis on food synergy. J Am Diet Assoc 101, 1416-1419.

6. Chakraborty S \& Bhattacharjee P (2017) Supercritical carbon dioxide extraction of melatonin from Brassica campestris: in vitro antioxidant, hypocholesterolemic and hypoglycaemic activities of the extracts. Int J Phar Sci Res 8, 2486-2495.

7. Paul K \& Bhattacharjee P (2018) Process optimization of supercritical carbon dioxide extraction of 1,8-cineole from small cardamom seeds by response surface methodology: in vitro antioxidant, antidiabetic and hypocholesterolemic activities of extracts. J Essent Oil Bear Pl 21, 317-329.

8. Kongo-Dia-Moukala JU, Nsor-Atindana J \& Hui Z (2011) Hypocholesterolemic activity and characterization of protein hydrolysates from defatted corn protein. Asian J Biochem 6, 439-449.

9. Bisson J, McAlpine JB, Friesen JB, et al. (2016) Can invalid bioactives undermine natural product-based drug discovery? J Med Chem 59, 1671-1690.

10. Bryda EC (2013) The Mighty Mouse: the impact of rodents on advances in biomedical research. Mo Med 110, 207-211.

11. Gundamaraju R, Hwi KK, Singla RK, et al. (2014) Antihyperlipidemic potential of Albizia amara (Roxb) Boiv. bark against Triton X-100 induced hyperlipidemic condition in rats. Pharmacognosy Res 6, 267-273.

12. Sudha SS, Karthic R \& Naveen JR (2011) Anti-hyperlipidemic activity of Spirulina platensis in Triton X-100 induced hyperlipidemic rats. Hygeia J D Med 3, 32-37.

13. Keshetty V, Pabba S, Rajyalakshmi G, et al. (2009) Antihyperlipidemic activity of methanolic extract of garlic (Allium sativum L.) in Triton X-100 induced hyperlipidemic rats. J Pharm Res 2, 777-780.

14. Kothiyal P \& Gupta AK (2011) Antihyperlipidemic activity of aqueous and ethanolic extracts of fruits of Kigelia africana (Lam.) Benth. in Triton X-100 induced hyperlipidemic rats. Pharmacologyonline 3, 386-395.

15. Patel JS, Setty SK, Chakraborty M, et al. (2011) Antihyperlipidemic activity of Medohar Vati in Triton X-100 induced hyperlipidemic rats. Int J Pharm Res Dev 4, 125-130.

16. Khan BA, Abraham A \& Leelamma S (1996) Biochemical response in rats to the addition of curry leaf (Murraya koenigiz) and mustard seeds (Brassica juncea) to the diet. Plant Foods Hum Nutr 49, 295-299.

17. Nagashree S, Archana KK, Srinivas P, et al. (2017) Anti-hypercholesterolemic influence of the spice cardamom (Elettaria cardamomum) in experimental rats. J Sci Food Agric 97, 3204-3210.

18. Halder D, Dan S, Pal M, et al. (2017) LC-MS/MS assay for quantitation of enalapril and enalaprilat in plasma for bioequivalence study in Indian subjects. Future Sci OA 3, FSO165.

19. Adams RP (2007) Identification of Essential Oil Components by Gas Chromatography/Mass Spectroscopy, 3rd ed. Carol Stream, IL: Allured Publishing Corp.

20. Linstrom P \& Mallard WG (2012) NIST Standard Reference Database Number 69. Gaithersburg, MD: National Institute of Standards and Technology. http://webbook.nist.gov/ (accessed August 2018).

21. Kuyumcu E \& Küçükba FZ (2013) Essential oil composition of Elettaria cardamomum Maton. I Appl Biol Sci 7, 42-45. 
22. Aiyegoro OA \& Okoh AI (2010) Preliminary phytochemical screening and in vitro antioxidant activities of the aqueous extract of Helichrysum longifolium. BMC Complement Altern Med 10, 2-8.

23. Chakraborty S \& Bhattacharjee P (2018) Design of lemon-mustard nutraceutical beverages based on synergism among antioxidants and in vitro antioxidative, hypoglycaemic and hypocholesterolemic activities: characterization and shelf life studies. J Food Meas Charact 12, 2110-2120.

24. OECD (Organization for Economic Co-operation and Development) (2001) 423: ECD Guideline for testing of chemicals: acute oral toxicity - acute toxic class method. https://ntp.niehs.nih.gov/iccvam/suppdocs/feddocs/oecd/oecd_gl423.pdf (accessed May 2017).

25. Olfert ED, Cross BM \& McWilliam AA (editors) (1993) Guide to the Care and Use of Experimental Animals. Ottawa: Canadian Council on Animal Care.

26. OECD (Organization for Economic Co-operation and Development) (2001) 425: OECD guideline for testing of chemicals: acute oral toxicity - up-and-down procedure. http://www. oecd.org/chemicalsafety/risk-assessment/1948378.pdf (accessed June 2017).

27. Itaya K \& Ui M (1965) Colorimetric determination of free fatty acids in biological fluids. J Lipid Res 6, 16-20.

28. Fossati P \& Prencipe L (1982) Serum triglyceride determined colorimetrically with an enzyme that produces hydrogen peroxide. Clin Chem 28, 2077-2080.

29. Kumari K, Mathew BC \& Augusti KT (1995) Antidiabetic and hypolipidemic effects of S-methyl cysteine sulfoxide isolated from Allium cepa Linn. Indian J Biochem Biophys 32, 49-54.

30. Ohkawa H, Ohishi N \& Yagi K (1979) Assay for lipid peroxides in animal tissues by thiobarbituric acid reaction. Anal Biochem 95, 351-358.

31. Shinde S, Chivate N, Kulkarni P, et al. (2013) Hypolipidemic activity of Psidium guajava Linn leaves extracts in hyperlipidemic rats. Int J Pharm Pharm Sci 5, 70-72.

32. Roy S, Das K, Mandal S, et al. (2014) Asparagus racemosus roots ameliorates acetaminophen induced hepatotoxicity in rats: an experimental, biochemical and histological study. Int J Rec Sci Res 5, 1192-1197.

33. Mallick S, Mandal M, Roy S, et al. (2016) Effect of phytosterol extract from sesame seed on experimentally Induced hyperlipidemic rats: dose dependent study. Int J Pharma Bio Sci 7, 370-377.

34. Namani S, Gogineni R, Bandi A, et al. (2016) Evaluation of non-HDL cholesterol and total cholesterol/HDL-C ratio, LDL-C/HDL-C ratio as cumulative marker of cardiovascular disease risk in type 2 diabetes mellitus patients. Int J Biomed Res 7, 680-684.

25. Shibib BA, Khan LA \& Rahman R (1993) Hypoglycaemic activity of Coccinia indica and Momordica charantia in diabetic rats: depression of the hepatic gluconeogenic enzymes glucose-6-phosphatase and fructose-1,6-bisphosphatase and elevation of both liver and red-cell shunt enzyme glucose-6-phosphate dehydrogenase. Biochem J 292, 267-270.

36. Rao AV \& Ramakrishnan S (1975) Indirect assessment of hydroxymethylglutaryl-CoA reductase (NADPH) activity in liver tissue. Clin Chem 21, 1523-1525.

37. Nair AB \& Jacob S (2016) A simple practice guide for dose conversion between animals and human. J Basic Clin Pharm 7, 27-31.

38. Huber J, Latzin S, Langguth $O$, et al. (1973) The influence of bilateral superior cervical ganglionectomy, continuous light and continuous darkness on the diurnal rhythm of hydroxymethylglutaryl-coenzyme a reductase in rat liver. FEBS Lett 31, 261-265.
39. Kim S, Thiessen PA, Bolton EE, et al. (2016) PubChem substance and compound databases. Nucleic Acids Res 44, 202-213.

40. Pettersen EF, Goddard TD, Huang CC, et al. (2004) UCSF Chimera - a visualization system for exploratory research and analysis. J Comput Chem 25, 1605-1612.

41. Miteva MA, Guyon F \& Tufféry P (2010) Efficient 3D conformation ensemble generator for small compounds. Nucleic Acids Res 38, 622-627.

42. Berman HM, Westbrook J, Feng Z, et al. (2000) The protein data bank. Nucleic Acids Res 28, 235-242.

43. Jones G, Willett P, Glen RC, et al. (1997) Development and validation of a genetic algorithm for flexible docking. J Mol Biol 267, 727-748.

44. Tian W, Chen C, Lei X, et al. (2018) CASTp 3.0: computed atlas of surface topography of proteins. Nucleic Acids Res 46, 363-367.

45. Huang B (2009) Metapocket: a meta approach to improve protein ligand binding site prediction. Omics 13, 325-330.

46. Laskowski RA \& Swindells MB (2011) Ligplot+: multiple ligandprotein interaction diagrams for drug discovery. J Chem Inf Model 51, 2778-2786.

47. Dyer JR (editor) (2012) Infrared spectroscopy. In Applications of Absorption Spectroscopy of Organic Compounds, 1st ed., pp. 143-160. Delhi: Prentice-Hall of India Pvt. Ltd.

48. Bio-Rad Laboratories (2018) SpectraBase: $\alpha$-terpinyl-acetate. http:// spectrabase.com/spectrum/76CgFOBF69G (accessed June 2018).

49. Bio-Rad Laboratories (2018) SpectraBase: $\alpha$-terpineol. http://spectrabase.com/spectrum/5glko5vslvB (accessed June 2018).

50. Boughendjioua H \& Djeddi S (2017) Fourier transformed infrared spectroscopy analysis of constituents of lemon essential oils from Algeria. AJOP 5, 30-35.

51. Bio-Rad Laboratories (2018) SpectraBase: 3,7-dimethyl-1,6octadien-3-ol. http://spectrabase.com/spectrum/BysYlv5n3w8 (accessed June 2018).

52. Bio-Rad Laboratories, Inc. (2018) SpectraBase ${ }^{\mathrm{TM}}$. http://spectrabase.com/ (accessed September 2018).

53. Pasha SR (2014) Evaluation of hypolipidemic activity of methanolic extract of Ficus dalhousiaemiq on Triton- $\mathrm{X}$ and high fat diet induced hyperlipidemia in albino rats. EJPMR 1, 183-191.

54. Yang R, Shi Y, Hao G, et al. (2008) Increasing oxidative stress with progressive hyperlipidemia in human: relation between malondialdehyde and atherogenic index. J Clin Biochem Nutr 43, 154-158.

55. Csonka C, Sárközy M, Pipicz M, et al. (2016) Modulation of hypercholesterolemia-induced oxidative/nitrative stress in the heart. Oxid Med Cell Longev 2016, 3863726.

56. Hussain SAR (2007) Effect of melatonin on cholesterol absorption in rats. J Pineal Res 42, 267-271.

57. Khor HT \& $\mathrm{Ng}$ TT (2000) Effects of administration of $\alpha$-tocopherol and tocotrienols on serum lipids and liver HMG CoA reductase activity. Int J Food Sci Nutr 51, 3-11.

58. Harwood HJ, Greene YJ \& Stacpoole PW (1986) Inhibition of human leukocyte 3-hydroxy-3-methylglutaryl coenzyme A reductase activity by ascorbic acid. An effect mediated by the free radical monodehydroascorbate. J Biol Chem 261, 7127-7135.

59. Lee J, Milmesser SH \& Carr TP (2003) Regulation of cellular cholesterol. In Molecular Nutrition, p. 314 J Zempleni and D Hannelore, editors]. Cambridge: CABI Publishing Series.

60. Esquifino A, Agrasal C, Velkzquez E, et al.. (1997) Effect of melatonin on serum cholesterol and phospholipid levels, and on prolactin, thyroid-stimulating hormone and thyroid hormone levels, in hyperprolactinemic rats. Life Sci 61, 1051-1058. 